\title{
Auditory interfaces in automated driving: an international survey
}

Pavlo Bazilinskyy, Joost C. F. De Winter

This study investigated peoples' opinion on auditory interfaces in contemporary cars and their willingness to be exposed to auditory feedback in automated driving. We used an Internet-based survey to collect 1,205 responses from 91 countries. The respondents stated their attitudes towards two existing auditory driver assistance systems, a parking assistant (PA) and a forward collision warning system (FCWS), as well as towards a futuristic augmented sound system (FS) proposed for fully automated driving. The respondents were positive towards the PA and FCWS, and rated the willingness to have automated versions of these systems as 3.87 and 3.77 , respectively (on a scale from $1=$ disagree strongly to $5=$ agree strongly). The respondents tolerated the FS (the mean willingness to use was 3.00 on the same scale). The results showed that among the available response options, the female voice was the most preferred feedback type for takeover requests in highly automated driving, regardless of whether the respondents' country was English speaking or not. The present results could be useful for designers of automated vehicles and other stakeholders. 
1 Auditory Interfaces in Automated Driving: an International Survey

\author{
Pavlo Bazilinskyy* and Joost de Winter \\ Department of Biomechanical Engineering, Faculty of Mechanical, Maritime and Materials Engineering, Delft \\ University of Technology, Mekelweg 2, 2628 CD, Delft, The Netherlands
}

\begin{abstract}
This study investigated peoples' opinion on auditory interfaces in contemporary cars and their willingness to be exposed to auditory feedback in automated driving. We used an Internet-based survey to collect 1,205 responses from 91 countries. The respondents stated their attitudes towards two existing auditory driver assistance systems, a parking assistant (PA) and a forward collision warning system (FCWS), as well as towards a futuristic augmented sound system (FS) proposed for fully automated driving. The respondents were positive towards the PA and FCWS, and rated the willingness to have automated versions of these systems as 3.87 and 3.77, respectively (on a scale from $1=$ disagree strongly to $5=$ agree strongly). The respondents tolerated the FS (the mean willingness to use was 3.00 on the same scale). The results showed that among the available response options, the female voice was the most preferred feedback type for takeover requests in highly automated driving, regardless of whether the respondents' country was English speaking or not. The present results could be useful for designers of automated vehicles and other stakeholders.

Practitioner Summary: In an Internet-based survey, peoples' opinion on auditory interfaces in contemporary cars and people's willingness to be exposed to auditory feedback in automated driving were evaluated. The results showed that a female voice was the most preferred feedback mode for takeover requests in highly automated driving.
\end{abstract}

\title{
Introduction
}

\section{The Development of Automated Driving Systems}

The development of automated driving technology is a key topic in modern transportation research. A transition to automated driving may have a large positive influence on society (European Commision, 2011). Each year more than 1,000,000 fatal accidents occur on roads worldwide, with the lower-income countries being overrepresented (Gururaj, 2008; World Health Organization, 2013). If automated driving systems are designed to be fully capable and reliable, a very large portion of - yet probably not all — road traffic accidents could be prevented (Goodall, 2014). Furthermore, traffic congestions, gas emissions, and fuel consumption may reduce considerably thanks to automated driving systems.

The control of vehicles can be represented as a spectrum consisting of five levels: (1) manual driving, (2) driver assistance, (3) partially automated driving, (4) highly automated driving, and (5) fully automated driving (Gasser \& Westhoff, 2012). The introduction of driver assistance systems (i.e., level 2 automation) to the public took place in the 1990s with the release of Adaptive Cruise Control (ACC), a system that automates the longitudinal motion of the vehicle (Beiker, 2012). Advancements in cameras, radars, lasers, and artificial intelligence have led to the creation of systems that make partially automated driving (i.e., level 3 automation) possible. Partially automated driving systems not only control the longitudinal motion of a vehicle, but

${ }^{*}$ Corresponding author. Email: P.Bazilinskyy@tudelft.nl 
also its lateral motion. Examples of such systems are BMW's Traffic Jam Assistant (BMW, 2013), Volvo's ACC with steer assist (Volvo, 2013a), and Mercedes' Distronic Plus with Steering Assist (Daimler, 2013). In partially automated driving, drivers are usually required to keep their eyes focused on the road and intermittently touch the steering wheel.

Highly automated driving (HAD; level 4 automation) is a next step. In HAD, the human can release the hands from the steering wheel and is no longer required to monitor the road permanently (e.g., Banks, Stanton, \& Harvey, 2014). However, humans still have an important role in the control of highly automated vehicles (Alicandri \& Moyer, 1992; Dingus, Hulse \& Barfield, 1998; Levitan, Golembiewski \& Bloomfield, 1998). In HAD, drivers can be asked to take over control of the vehicle when required, for example, when the vehicle automation cannot solve a task in a demanding traffic environment. The time between issuing a 'takeover request' and the required moment of transition of control from the vehicle to the human is a critical design parameter (Gold et al., 2013). If the driver spends too much time on reclaiming the control of the vehicle, or if the driver does not comprehend the warning signal sent by the vehicle, an accident may result. Clearly, the design of appropriate feedback is essential for the successful introduction of HAD to the public roads. Indeed, inappropriate feedback is regarded as a primary cause of automation-induced accidents (Norman, 1990).

Fully automated driving (FAD; level 5 automation) will be the next and final iteration in automated driving. People have been envisioning this step in the development of transportation for a long time. Almost half a millennium ago, Leonardo Da Vinci envisioned a pre-programmed clockwork cart (Weber, 2014). In 1939 during the New York World's Fair, General Motors presented their vision of the world 20 years into the future (1959-1960). In their Futurama exhibition, they introduced a concept of automated highways with trench-like lanes for separating traffic (Wetmore, 2003). In 1953, the futurist Isaac Asimov wrote a short story 'Sally' that pictured a situation where only cars that did not require a human driver were allowed on the roads.

FAD offers numerous potential benefits. It could reduce stress and allow the operator to engage in non-driving tasks such as working, using in-vehicle entertainment, or resting (e.g., Jamson et al., 2011; Llaneras, Salinger, \& Green, 2013). Furthermore, FAD is a recommended solution for achieving an optimal traffic flow, for example by means of platooning on highways (Bergenhem et al., 2012; Varaiya, 1993). The Google Driverless Car is one of the existing prototypes of FAD (Markoff, 2010). However, this particular vehicle does not fully comply with the principles of FAD; in reality, the Google Driverless Car relies on accurate three-dimensional maps of the environment and currently cannot cope with all dynamic environments of high complexity. It requires considerable advances in sensing and artificial intelligence before FAD becomes practically feasible on all public roads. Continental, a leading German manufacturer specialising on components for automotive industry, predicts that FAD will be launched in the year 2025 (Continental, 2012), whereas some voices have argued that FAD will never happen (Gomes, 2014; Underwood, 2014; Yoshida, 2014).

Although automated driving systems are expected to improve safety, certain side effects may occur regarding the human factor (e.g., Bainbridge, 1983; Desmond, Hancock, \& Monette, 1998; Merat et al., 2012; Brandenburg \& Skottke, 2014). A degraded reaction time to critical events 
has been found among drivers exposed to ACC (Stanton, Young, \& McCaulder, 1997; Stanton et al., 2001; Rudin-Brown \& Parker, 2004; Larsson, Kircher, \& Hultgren, 2014), and this issue is likely to be aggravated in higher levels of automated driving (De Winter et al., 2014; Strand et al., 2014). Furthermore, it is expected that people who will be driving highly and fully automated cars will suffer from a reduction of their manual control skills, similar to pilots in highly automated airplanes (Ebbatson, 2009; Scallen, Hancock \& Duley, 1995). The development of effective feedback systems is considered important in supporting operator's sustained attention, also called vigilance (Heikoop et al., 2015).

\section{Auditory Displays}

As mentioned above, unless the driving task is fully automated, an appropriate feedback system is required that warns and/or informs the human when automation mode changes are required. The present study investigated the potential of auditory feedback in automated driving. The auditory modality has several important characteristics: (1) it is omnidirectional. That is, unlike visual cues, auditory cues can be received from any direction. This is especially important in automated driving, during which the driver may not be attending to the road and dashboard; (2) the auditory sense can receive information at almost all times; (3) sound is transient, that is, unlike visual information which can be continuously available, information passed in the form of sound is only available at that particular moment; (4) although auditory cues may be masked by other sounds, humans have the ability to selectively focus on one sound when multiple streams of sound are available, also known as the cocktail party effect (Bregman, 1990; Cooke \& Ellis, 2001; Hermann, Hunt \& Neuhoff, 2011; Wickens \& Hollands, 2013).

An advantage of sound is that it is possible to use language, which may be more informative as compared to the information conveyed with haptic or visual interfaces. Because of the aforementioned qualities of sound, auditory displays are used in a variety of applications, especially in those cases where the user needs to be alerted or where additional visual load has to be avoided. For example, the majority of present route navigation devices use voice and sound messages to give directions to their users (Holland, Morse \& Gedenryd, 2002), and flight crews use auditory signals to get informed about proximate aircraft or to obtain directional information (e.g., Begault, 1993; Bronkhorst, Veltman \& Van Breda, 1996). An auditory interface in combination with tactile feedback was suggested in a driving simulator study (Ho, Reed \& Spence, 2007) as an optimal warning system for collision avoidance. The auditory modality has potential not only as a warning method, but also for providing inputs to the machine (e.g., speech interfaces). Literature reviews (Stanton \& Edworthy, 1999; Barón \& Green, 2006) suggest that people driver 'better' (i.e., lower lane variation, steadier speed) when auditory interfaces are employed in a manually driven car.

Auditory feedback can be delivered as a pre-recorded voice or as an artificial sound warning/message. The term earcon refers to a brief auditory message (e.g., a tune or a sound of a bell) that represents a certain event or object. Earcons have been introduced to desktop computers to complement visual icons (Mynatt, 1990; Belz, Robinson \& Casali, 1999; Hermann, Hunt \& Neuhoff, 2011). Previous research has shown that a female voice is favoured over a male voice in route navigation devices (Large \& Burnett, 2013). However, national or cultural differences seem to exist, where in some cases, the male voice is preferred over the female voice. In 2010, BMW supposedly had to recall its navigating system in Germany because male drivers 
disliked the idea of following orders communicated via a female voice (Takayama \& Nass, 2008), and Apple recently added the option of a male voice to their voice control system Siri (Bosker, 2013). In a driving simulator study by Jonsson and Dahlbäck (2011), non-native speakers of English responded more accurately to route instructions provided by a female voice than to route instructions provided by a male voice.

\section{Auditory Systems in Current Vehicles: Parking Assistant and Forward Collision Warning System}

Modern vehicles often include level 2 automation systems, which assist in driving and increase road safety. Such systems support drivers by providing auditory/visual/haptic warning messages and by taking over control of some of the driving tasks. In the present survey, we investigated the opinion of people on two existing auditory systems: a parking assistant (PA) and a forward collision warning system (FCWS).

The first generations of PAs were so-called parking sensors, which produce warning sounds (beeps) when the car gets too close to a nearby object while parking, using ultrasonic or electromagnetic sensors (BMW, 2013; Toyota, 2014; Volkswagen, 2014). Some recent PA systems take over the positioning of the vehicle during parking, leaving the control of acceleration and deceleration to the driver (Volkswagen, 2014). Other PAs take over control of the parking process entirely, as can be seen in the Toyota Prius 2015 and BMW X5 (BMW, 2014; Toyota, 2014).

A FCWS is a system that provides a warning sound when a vehicle is rapidly approaching a vehicle in front. FCWSs have the potential to prevent a large portion of rear-end collisions (Jamson, Lai \& Carsten, 2008; Kingsley, 2009; Kessler et al., 2012). If a potential accident is detected by the FCWS, the system either gives a warning to a driver (Honda, 2014) or engages in emergency braking and/or steers way from the object (Volvo, 2013b). Most FCWS detect vehicles with the help of computer vision (Srinivasa, 2002; Dagan et al., 2004), an approach that is used by companies like Honda and BMW (BMW, 2013; Volvo, 2013b; Honda, 2014) and/or radars (Volvo, 2013b; Ford, 2014; Honda, 2014; Mercedes-Benz, 2014). Both approaches have limitations, and the system may not issue warnings or stop the vehicle in bad weather or in other situations where the sensors are obscured by external factors. The introduction of vehicle-tovehicle (V2V) communication may increase the efficiency and capabilities of collision warning systems (e.g., Miller \& Huang, 2002). Eighty-eight percent of owners of Volvo cars surveyed by Braitman et al. (2010) reported always having the FCWS turned on.

It is expected that both PAs and FCWSs will remain in future partially and highly automated vehicles. However, these technologies will become obsolete with the introduction of FAD because both parking and collision avoidance will be handled without any input from the human driver.

\section{'Augmented / Spatial' Sound System for Fully Automated Driving}

Auditory warning signals will not be required in FAD, because in FAD the automation by definition takes care of all possible emergency conditions. This study proposes an experimental setup aimed at the three-dimensional augmentation of sound surrounding a vehicle, hereafter 
referred to as the 'future system' (FS), which could be used in FAD for entertainment and comfort. Three-dimensional sound is being developed as a means for providing feedback to humans (Lumbreras, Sánchez \& Barcia, 1996; Garas, 2000; Rozier, 2000; Godinho, António \& Tadeu, 2001; Dobler, Haller \& Stampfl, 2002).

Our proposed FS filters out unwanted sounds (e.g., tire/engine noise coming from vehicles in the vicinity) and amplifies desired sounds (e.g., sound of birds singing in a park). We envision that such a system could be used in future fully automated vehicles. Vehicles driving fully automatically have full control of the vehicle and must have reliable detection capabilities of the environment. Drivers of such vehicles will not be required to pay attention to the processes that take place in the environment surrounding the car. Hence, a spatial augmentation of sounds that a driver prefers to hear and simultaneous cancelation of unwanted sounds may enhance the pleasure of being engaged in FAD. Such system will probably have to be configurable: drivers must have the option to select which sounds they want to augment and which sounds they wish to filter out, as well to adjust the volume of these sounds.

\section{The Aim of the Present Survey Study}

As mentioned above, feedback is important in HAD, especially regarding transitions of control. It is relevant for the development of automated driving systems to know what types of interfaces people want and need. Because automated cars do not exist yet on the consumer market, it is impossible to test such research questions in an ecologically valid environment, except through driving simulator research.

The present study was undertaken from a different point of view. We proceeded on the basis that respondents were asked to imagine automated driving scenarios. The aim of the present study was to investigate the opinion of people on two existing auditory displays (PA \& FCWS) as well as the augmented sound system 'FS'. The respondents were asked to judge two qualities of the systems-helpfulness and annoyance-and state whether they would consider using such systems in the future. In addition, we asked people to report their preferred type of feedback for takeover requests in HAD. Statistical associations between self-reported driving style as measured with the Driver Behaviour Questionnaire (DBQ), yearly mileage, number of accidents, and opinions of respondents on the qualities of the proposed systems were assessed.

The hypothesis that people from non-English speaking countries prefer a female voice to a male voice in automated driving systems was also tested. Additionally, the respondents were asked to provide their general thoughts on the concept of automated driving in a free-response question. Finally, the respondents provided their opinion on the year of introduction of fully automated driving in their country of residence. Results of these analyses were compared with findings from two previous surveys that asked questions related to other aspects of automated vehicles (De Winter et al., 2015; Kyriakidis, Happee, \& De Winter, 2015).

\section{Methods}

\section{Survey}

A survey containing 31 questions was developed with the online tool CrowdFlower (www.crowdflower.com). Table 1 shows the questions of the survey as well as the corresponding 
coding. The full survey is included in the supplementary material. The survey was targeted towards reasonably educated persons without knowledge of automated driving. A previous survey indicated that people who work on CrowdFlower-based surveys have mostly undergraduate degrees (Kyriakidis et al., 2015).

The present survey introduced in plain language three levels of driving: manual driving, partially automated driving, and fully automated driving. Manual driving was referred to as "normal (non automated) cars". The explanation of partially driving was provided as follows: "Imagine again that you are driving in an automated car (that can perform certain tasks without any interaction from the humans in the car). However, the automation cannot handle all possible situations, and you sometimes have to take over control". Respondents were asked to imagine fully automated driving as follows: "Imagine a fully automated car (no steering wheel) that drives completely on its own with no manual interaction".

The survey contained questions on the person's age, gender, driving frequency, mileage, and accident involvement. The questions asking participants to provide information on their driving style were based on the violations scale of the DBQ, as used by De Winter (2013).

The respondents were asked to express their opinion on two currently existing systems and one proposed setup that could be used during fully automated driving. Specifically, we asked respondents about (1) a parking assistant (PA) in a manually driven car that produces warning sounds (beeps) when the car gets too close to a nearby object while parking, (2) a forward collision warning system (FCWS) in a manually driven car that provides a warning sound when a car is rapidly approaching another car in front, and (3) a future augmented surround sound system in a fully automated vehicle (FS). The FS was described as follows: "Now imagine that this fully automated car records what is happening outside and plays it via speakers inside the car, informing the occupants about the outside environment. In other words, those who sit in the car can hear what is happening outside even when their windows are closed. Sound volume in such system could be adjusted; particular noise (for example sound coming from another vehicle) could be filtered out. Such system could, for example, be used during a leisure drive through a park on a hot day". Illustrations belonging to the three scenarios (i.e., PA, FCWS, FS) were used in the survey (Figure 1). No auditory examples were used. The illustrations were uploaded to a remote site in order to be embedded to the survey. Supplementary material contains the XML code used to create the survey. If one wishes to add images to a CrowdFlower survey, the suggested method could be used.

Figure 1. Illustrations belonging to the three scenarios presented to the respondents. (a) Parking assistant (PA); (b) Forward collision warning system (FCWS); (c) Future system (FS).

The respondents were asked to indicate disadvantages of the PA (Q17) and FCWS (Q23) and to indicate advantages and disadvantages of the FS (Q26) by means of textual responses. The respondents also had the opportunity to indicate the preferred mode of feedback for receiving a takeover request (Q27 \& Q28). In the last question (Q31), they were asked to "provide any suggestions, which could help engineers to build safe and enjoyable automated cars". Giving a response to this last free-response question was optional. All examples of given comments 
shown in this article are direct quotes from the responses; no grammatical or syntactic errors were corrected. The respondents had to complete all questions (except Q28 \& Q31), and each question had an I prefer not to respond response option.

Table 1. All survey items.

\section{Configuration of CrowdFlower}

In the instructions, the respondents were informed that they would need approximately 10 min to complete the survey. The task expiration time was set to $30 \mathrm{~min}$. Contributors from all countries were allowed to participate in the survey, in order to collect data from an as large and diverse population as possible. Moreover, the lowest level of experience of contributors 'Level 1 contributors' was selected. This level of experience accounts for $60 \%$ of completed work on CrowdFlower. As a result, the survey was available to a large number of workers, which allowed reaching a relatively diverse group of users of the platform. Completing the survey more than once from the same IP address was allowed (note, however, that responses from multiple IP addresses were filtered out in our analyses, see results section). For the completion of the survey a payment of $\$ 0.15$ was offered, and 2,000 responses were collected. The study was preceded by a pilot test with 10 respondents. The pilot test did not lead to any changes in the survey, and these 10 respondents were not included in the analysis.

\section{Analyses}

Descriptive statistics (i.e., mean, median, standard deviation, skewness, and number of responses) were calculated for each of the variables. The skewness was calculated as the third central moment divided by the cube of the standard deviation. A Spearman correlation matrix among the variables was created. The first author manually performed the analysis of textual responses (Q17, Q23, Q26, Q28, \& Q31).

CrowdFlower automatically provides the respondent's country based on his/her IP address. We analysed the preferences of people from English speaking countries, as defined by the UK government (UK Visas \& Immigration, 2014): Antigua and Barbuda, Australia, Bahamas, Barbados, Belize, Canada, Dominica, Grenada, Ireland, Jamaica, New Zealand, Saint Lucia, Trinidad and Tobago, United Kingdom, and the United States) versus non-English speaking countries regarding the use of a male or female voice for supporting takeover requests during highly automated driving. Supplementary material contains the MATLAB script used to analyse the data.

\section{Ethics Statement}

All data were collected anonymously. The research was approved by the Human Research Ethics Committee (HREC) of the Delft University of Technology. Documented informed consent was obtained via a dedicated survey item asking whether the respondent had read and understood the survey instructions.

\section{Results}

\section{Number of Respondents and Respondent Satisfaction}


In total, 2,000 surveys were completed. The responses were gathered on 2 September 2014 between 15:00 and 20:15 (CET). The survey received an overall satisfaction rating of 4.4 out of 5.0. Additionally, the respondents ranked clearness of the instructions as $4.4 / 5.0$, fairness of the questions as 4.2 / 5.0, easiness of the survey as 4.2 / 5.0, and the offered payment as 4.1 / 5.0.

\section{6}

\section{Data Filtering}

The respondents who indicated they had not read the instructions $(N=10)$, who indicated they were under 18 and thereby did not adhere to the survey instructions $(N=6)$, who chose the $I$ prefer not to respond or I do not know options in one or more of the multiple choice questions $(N$ =231), who indicated they never drive $(N=193)$, or who indicated they drive $0 \mathrm{~km}$ per year $(N$ $=191)$ were excluded from the analyses. Since no limitations were applied on the number of responses that could be generated per IP address, some people completed the survey more than once. Such behaviour was seen as an indication that these persons participated in the survey primarily because of monetary gain. Thus, we applied a strict filter, and all data generated from non-unique IP address were removed $(N=465)$. In total, 795 surveys were removed, leaving 1,205 completed surveys for further analysis.

For the question "In which year do you think that most cars will be able to drive fully automatically in your country of residence?", non-numeric responses (e.g., a year complemented by words such as "maybe 2030", or "never") and answers before the year 2014 were excluded, leaving 1,082 numeric responses.

\section{Analyses at the Individual Level}

The 1,205 respondents were from 91 countries (all 2,000 responses were associated with 95 countries). Descriptive statistics for all variables are listed in Table 2. The respondents took on average 9.2 minutes to complete the survey $(S D=5.6 \mathrm{~min}$, median $=7.7 \mathrm{~min})$. The supplementary material contains the entire Spearman correlation matrix. The correlation coefficients between variables that related to questions about the PA, FCWS, and FS (PApast, PAhelp, PAannoy, PAfut, FCWSpast, FCWShelp, FCWSannoy, FCWSfut, FSannoy, \& FSfut) on the one hand, and Age, DriveFreq, KmYear, NrAcc, the DBQ variables (Vangered, Vmotorway, Vresident, Vfollowing, Vrace, Vhorn, \& Vphone), YearAuto, and SurvTime, on the other, were overall small, between -0.15 and 0.25 .

Table 2. Descriptive statistics for the survey items $(N=1,205)$.

The respondents' mean and median age were 31.9 and 30 years, respectively. Figure 2 shows the distribution of the respondents in 5-year wide age groups. $75.2 \%$ of the respondents were male (906 men vs. 299 women). The frequencies of the answers are provided in Table 3.

Table 3. Frequencies of answers. 
Figure 3 shows that the respondents expected most cars to be able to drive in fully automated mode in their countries of residence around 2030 (median response), with a highly skewed distribution.

Figure 2. Distribution of the age of the respondents aged between 18 and 54 years.

Figure 3. Distribution of responses for the question: "In which year do you think that most cars will be able to drive fully automatically in your country of residence?" (Q30). Years were divided into 5-year-wide bins.

The respondents were asked to provide their opinion on two characteristics of the PA and FCWS systems, annoyance and helpfulness, and whether they would be willing to have automated versions of such systems in their own cars (Q18 for the PA \& Q22 for the FCWS), all questions on a scale from 1 (disagree strongly) to 5 (agree strongly). Figure 4 shows the results for these questions.

Figure 4. Opinion of the respondents on whether a PA and FCWS are helpful and annoying, and whether they would like to have automated versions of such systems in their cars in the future.

Figure 5 shows associations between the opinion of the respondents on annoyance and helpfulness of the PA and FCWS and their age divided into 5-year wide bins. Figure 5a shows that younger respondents found that both the PA $(\rho=-0.05, p=.103)$ and the FCWS $(\rho=-0.14$, $p<.001$ ) were more annoying, but these effects were weak. The Spearman correlation between the respondents' age and the reported annoyance of the FS was weak as well $(\rho=0.06, p=.035)$. Figure $5 \mathrm{~b}$ shows that the perceived helpfulness of the FCWS $(\rho=0.12, p<.001)$ slightly increased with age. People who found the PA annoying typically indicated that the FCWS was also annoying $(\rho=0.47, p<.001)$, and respondents who thought that the PA was helpful, considered the FCWS to be helpful as well $(\rho=0.34, p<.001)$.

Figure 5. (a) Opinion on the annoyance of the parking assistant (PA, Q16), forward collision warning system (FCWS, Q21), and future system (FS, Q24) as a function of age; (b) Opinion on the helpfulness of the PA (Q15) and FCWS (Q20) as a function of age. Age was divided into 5-year-wide bins.

Figure 6 shows the respondents' opinion on the proposed future system. The respondents were asked whether they would find such system annoying (Q24) and whether they would prefer to use such system instead of opening windows while driving in a fully automated car through a scenic place (Q25). A large portion of the respondents was neutral in their responses: 346 people choose the option Neither agree nor disagree in Q24, and 312 persons chose the same option in Q25.

Figure 6. Distribution of opinions on whether the proposed future system (FS) would be annoying (Q24) and whether the respondents would prefer the system to opening windows in fully automated cars (Q25). 
In Q27 the respondents were asked to report on the types of feedback that they would like to be supported by in case of a takeover request during highly automated driving. The respondents were allowed to select multiple options. Figure 7 shows that a large number of people preferred auditory feedback represented as a female voice saying 'Take over please' $(N=514)$. The number of respondents who chose the option with the male voice was considerably lower $(N=$ 244). Figure 7 makes a distinction between the numbers of female and male respondents. It is apparent that both female and male respondents preferred the female over the male voice.

Other types of auditory feedback were reported in the following order: two beeps $(N=375)$, one beep $(N=195)$, a bell sound $(N=194)$, and a horn sound $(N=135)$. The respondents indicated a high level of support for both visual signals offered in the question: a warning message projected on the windscreen 'Take over please' $(N=429)$ and a warning light $(N=406)$. However, respondents showed a relatively low level of acceptance of the offered variations of a vibration interface: vibrations in the seat $(N=341)$, vibrations in the steering wheel $(N=179)$, vibrations in the seatbelt $(N=117)$, and vibrations in the floor $(N=64)$. Furthermore, the results seem to suggest that female respondents were less likely than male respondents to prefer a female voice.

Figure 7. Numbers of respondents who indicated a preference for a particular takeover request during highly automated driving in the question: "Now imagine again that you are driving in an automated car (that can perform certain tasks without any interaction from the humans in the car). However, the automation cannot handle all possible situations, and you sometimes have to take over control. What type of warning signal would you like to receive in case manual take over is required?" (Q27). Each bar is supplemented by the corresponding 'risk ratios' of female respondents, calculated as the proportion of females who indicated this answer divided by the number of males who indicated this answer. If the risk ratio is greater than 1 females are overrepresented. Conversely, if the risk ratio is smaller than 1 , females are underrepresented. $95 \%$ confidence intervals are shown in parentheses.

Figure 8 shows the opinion of the respondents on the combinations of warning signals. The figure shows that most people $(N=188)$ preferred a sound signal (i.e., one or two beeps, a horn, or bell) without additional information. A large number of people indicated that they would like to receive a combination of all four modalities $(N=170)$ or the combination of a sound signal, a visual message, and a voice $(N=101)$.

Figure 8. Preference to combinations of types of signals for aiding takeover requests during highly automated driving (Q27). All possible combinations are listed. Hence, the total number of respondents adds up to 1,205.

\section{Cross-National Differences in Opinion for Feedback for Takeover Requests}

Next, we tested the hypothesis whether peoples' preference for a female and male voice in supporting takeover requests in highly automated driving was different between English and non-English speaking countries. Figure 9 presents a scatter plot, showing the numbers of respondents per country who indicated that they would like to receive a female or a male voice. The overall percentage of respondents who expressed preference for a female voice was $43 \%$ $(514 / 1,205)$, and the overall percentage of people who expressed preference for a male voice was $20 \%(244 / 1,205)$. The corresponding percentages were $42 \%(71 / 168)$ and $22 \%(37 / 168)$ for English speaking countries, and they were 43\% (443 / 1,037) and 20\% (207 / 1,037) for nonEnglish speaking countries. The differences between English speaking countries and non-English 
speaking countries were not statistically significant (female voice: $\mathrm{RR}=0.99,95 \% \mathrm{CI}=[0.82$, 1.20]; male voice: $\mathrm{RR}=1.10,95 \% \mathrm{CI}=[0.81,1.50])$.

\begin{abstract}
Figure 9. Numbers of respondents from English and non-English speaking countries who indicated a preference for a male voice and a female voice for a takeover request during highly automated driving (Q27). The dashed line represents the ratio between the number of respondents who preferred a female voice and the number of respondents who preferred a male voice. The solid line is the line of unity. No labels for shown for countries with five or less respondents indicating a male voice, to support the clarity of the figure. Country abbreviations are listed according to ISO 3166-1 alpha-3.
\end{abstract}

\title{
Analyses of Textual Comments
}

The respondents provided their feedback on the disadvantages of the PA in Q17. The responses that were less than five characters long $(N=181)$ or that were not written in English $(N=39)$ were ignored. Comments were processed before data filtering and were hence based on all 2,000 responses. $12.4 \%$ of the respondents $(N=151)$ provided negative feedback on the auditory interfaces in parking assistants. Many people $(N=135)$ indicated that PA systems were annoying, for example: "Sound should not be too loud and annoying" and "I think it could be annoying especially when your focusing". Thirty-seven respondents pointed out that the PA used overly loud sounds. Next, a selection of answers to the question contained comments that the PA sounds can be distracting $(N=21)$ and inaccurate $(N=48)$. Five respondents indicated that they would prefer feedback in other types of modalities, for example: "annoying, use something else instead of the constant loud beeping sounds" and "The sound, a voice message would be better". Five respondents indicated that the PA systems cannot be used by deaf people.

The respondents indicated their opinion on the disadvantages of the FCWS in Q23. The responses that were less than five characters long $(N=276)$ or that were not written in English $(N=35)$ were not included in the analysis. Sixteen respondents indicated that the auditory feedback used in FCWS was annoying, for example: "This situation might come up too often so the warning sound may get annoying fast" and "The beeps might feel annoying".

Next, the respondents were asked to comment on possible advantages and disadvantages of the FS in Q26. The responses that were less than five characters long $(N=138)$ or that were not written in English $(N=46)$ were not included in the analysis. In total, 1,249 comments were analysed. A collection of mixed responses was received. Overall, more comments were classified as positive $(N=132)$ than negative $(N=52)$ to the FS. However, the respondents also pointed out concerns about a number of characteristics that they associated with the system: annoyance to both a driver and to other road users in the traffic $(N=101)$, distraction $(N=47)$, and loudness $(N=28)$. Fifty-five respondents expressed their concerns that the system would be impractical; however, most of such concerns could be associated with the lack of understanding of the concept of a fully automated car. Certain respondents showed a high level of negativity caused by an apparent lack of understanding the concept of filtering only specific sounds coming from the outside environment. Examples are: "You can not hear some bells or signal from other cars", "Main disadvantage: makes driver unaware of any dangers", "If car noises are filtered out how would you hear if another car is incoming", and "I feel that filtering other car noise may be dangerous". 
In Q27 the respondents were asked to indicate their preference for types of interfaces to be used for takeover requests in HAD. One of the options in that question was "Other". If respondents selected this option, they were invited to provide further comments in Q28. The responses that were less than five characters long $(N=32)$ or that were not written in English $(N=1)$ were ignored. In total, 22 responses were analysed. One respondent indicated that he/she would prefer to be aided by continuous beeps until he/she reclaimed control. Another respondent stated "steering wheel up or down motion to signal steering wheel usage needed, accompanied by a specific message". One respondent mentioned that interfaces used in such scenario need to be adaptive depending on the urgency of the request "It honestly depends on the situation the car needs me to take over for. Does it affect anyone's safety at all? Does it actually /need/ to be done straight away? Is it critically important in any other way? In those cases I'd obviously like a very noticeable signal however 'annoying' it may be. In other situations however I'd prefer a decent text message or a gentle reminder".

\section{Discussion}

The aim of this study was to obtain opinions on preferred feedback types for takeover requests in HAD from a large number of people coming from all over the globe. Additionally, the aim was to measure perceived helpfulness and annoyance of auditory interfaces for three systems. Specifically, the respondents who participated in the survey were presented with two existing systems used in modern vehicles (a parking assistant [PA] \& forward collision warning system [FCWS]) and one futuristic setup (FS) envisioned for FAD. Respondents were asked whether they would consider using the proposed FS in future automated vehicles. Our survey helped us to gather opinions from people before technology is actually available.

Previous research suggests that the modality of aiding systems in automated cars should be chosen carefully to avoid frustration of people who will be using such vehicles and to increase safety of automation on public roads. Stanton, Young, and McCaulder (1997) expressed concerns that interfaces currently employed in ACC do not support the understanding of the behaviour and limitations of the system. A driving simulator study by Adell et al. (2008) provided a comprehensive analysis of combinations of interfaces for supporting safe driving. Participants in that study were most positive about the haptic interface, while the auditory warning signals were not highly appreciated, which may be explained by the nature of the experiment that exposed the participants to a high urgency scenario of avoiding rear-end collisions (Adell et al., 2008).

Findings from the aviation field show that the female voice is more difficult to understand in noisy environments (Nixon et al., 1998a). It has also been argued that the female voice has the advantage that it stands out more in a predominantly male environment, such as the military (Noyes, Hellier, \& Edworthy, 2006). However, differences in speech intelligibility and perceived urgency between male and female voices are generally small and findings have been mixed (e.g., Arrabito, 2009; Edworthy, Hellier, \& Rivers, 2003; Nixon et al., 1998b). However, it has been found that most people normally use a female voice when using their route navigation device (Large \& Burnett, 2013). In the present research, respondents were asked to select the types of interfaces they are willing to be guided by during a takeover request. The results of our survey further showed that the female voice is preferred in both English and non-English speaking 
countries. Thus, our findings reinforce the idea that the overall most preferred way to support the transition of control is an auditory instruction performed with a female voice. However, determining the language of respondents based on their IP address cannot guarantee accurate results in all cases. In future surveys adding a question prompting for the participant's spoken language may yield more accurate results.

It was found that the participants showed a relatively low level of appreciation of vibratory interfaces, which contrasts with the findings in Adell et al. (2008). This could be due to the fact that only a small number of systems that feature vibratory feedback are available in modern vehicles. A relatively large number of people indicated that they would like to be aided by all four proposed modalities. In addition, a large number of respondents indicated that the combination of a sound signal, a visual message, and a vibration signal would be preferable during takeover requests in highly automated driving. This is a surprising finding as such a combination is not common in current cars. A possible explanation of this finding could be that the respondents misinterpreted the question and instead of indicating their preference for multimodal feedback, expressed their preferences for the types of feedback that can be used separately from each other during takeover requests in highly automated driving. Another limitation of the present study is that we did not vary possible parameters of the feedback signals, including the quality, intensity, timing, and speed of delivery of the take-over requests. Future experimental research could investigate the effects of such parameters.

The existing systems - the PA and FCWS - received favourable ratings, which may not be surprising, since these systems have already been tested and are already available on the market. One limitation in this context is that the participants relied on a narrative description, complemented with a visual illustration; the survey did not contain actual examples of auditory cues. Before the initiation of the survey, it was believed that the proposed FS would be seen as a way to enhance the enjoyment of driving a car through a scenic place. The results showed that the participants were rather sceptical about such a concept: the system was perceived as somewhat annoying, with a mean score of 3.21 to question Q24 on the scale from disagree strongly (1) to agree strongly (5). The proposed FS was not highly rated, possibly because the concept was perceived as a bad idea, because of a lack of previous experience with such system, or because people could not envision it due to the lack of a realistic representation (see also the analysis of the textual comments). It should also be noted that a large proportion of respondents selected the middle option Neither agree nor disagree, possibly indicating difficulties with understanding the concept of the proposed system (for studies into middle category endorsement, see Kulas, Stachowski \& Haynes, 2008; Kulas \& Stachowski, 2009; Sturgis, Roberts \& Smith, 2012).

Small effects of age on the acceptance of FAD were previously reported by Payre, Cestac and Delhomme (2014). In the present study, we also observed small age effects regarding the selfreported annoyance of the three proposed systems: younger participants saw the PA and FCWS as more annoying than older respondents did. However, young respondents perceived the FS as less annoying than the older respondents. It is known that younger people are more likely to accept new technologies (Lee, 2007; Tacken et al., 2005), and thus may be more successful at envisioning such abstract concepts as the FS. A somewhat stronger age effect was observed regarding helpfulness: older respondents found the FCWS more helpful than the younger participants. It is known that young people feel more confident behind the wheel (Matthews \& 
Moran, 1986; Lee et al., 2002; Lee, 2007; Clarke, Ward \& Truman, 2005), and therefore may think they need less external help than older drivers.

CrowdFlower offers a platform that supports full anonymity of participants. This anonymity may have encouraged respondents to express their thoughts freely, without the fear of being judged by the organizers of the survey. All but the last free-response items required people to enter at least one character. A large number of respondents did not provide meaningful comments. However, a substantial portion of respondents did provide valuable answers, facilitating the understanding of what people think about not only the use of auditory interfaces in future highly and fully automated cars, but also about the concept of automated driving in general. Numerous respondents expressed their concerns about the qualities of current PA and FCWS systems. Some participants suggested that they want to be aided by visual and vibratory feedback in addition to auditory feedback. A number of people indicated the inaccessibility of modern PAs and FCWSs to deaf users. However, current systems also provide haptic and/or visual cues (BMW, 2013; Volvo, 2013b; Ford, 2014; Honda, 2014), and so people with a hearing impairment could still benefit from such multimodal feedback. Some respondents were sceptical about the introduction of highly and fully automated vehicles, which may be related to general consumer scepticism about new technologies. Respondents expected that most cars would drive fully automatically by the year 2030 (median value), a result that matches findings in previously published research (Sommer, 2013; De Winter et al., 2015; Kyriakidis et al., 2015).

The total cost of the study performed by means of a crowdsourced online-based survey was lower than what is offered by companies that conduct similar surveys with help of classic recruitment methods (De Winter et al., 2015). A group of people filled in the survey more than once, and we reasoned that their responses ought not to be trusted. Thus, we applied a strict filter, and removed all respondents who filled out the survey more than once. We also excluded all people who had one or more missing items. With appropriate data quality control mechanisms, crowdsourcing is known to be a powerful research tool (Howe, 2006; Kittur, Chi \& Suh, 2008; Mason \& Suri, 2012; Crump, McDonnell \& Gureckis, 2013). Nonetheless, as with any self-report questionnaire, the validity of the results is limited to what people can imagine or retrieve from their memory. Furthermore, CrowdFlower respondents are not representative of the entire population of stakeholders of future HAD cars. It is likely that highly automated vehicles will initially be purchased by wealthy people, while projects on CrowdFlower are often completed by people from low-income countries (Kyriakidis et al., 2015).

In conclusion, the present survey study showed that the PA and FCWS were well appreciated by respondents, whereas the proposed future system (FS) was not rated highly. A second conclusion is that the female voice is the most preferred take over request among the offered options. The scientific community and the automotive industry may be able to use the information gathered in the present survey for the development of automated driving systems, in particular future iterations of parking assistants and forward collision warning systems, as well as for the design of human-machine interfaces for automated driving.

\section{Acknowledgements}

The research presented in this paper was conducted in the project HFAuto - Human Factors of Automated Driving (PITN-GA-2013-605817). We would like to express our special gratitude to 
611 Daria Nikulina for designing the illustrations used in the survey.

612

613

614

615

616

617

618

619

620

621

622

623

624

625

626

627

628

629

630

631

632

633

634

635

636

637

638

639

640

641

642

643

644

\section{References}

Adell E, Varhelyi A, Fontana MD, Bruel L. 2008. Test of HMI alternatives for driver support to keep safe speed and safe distance - a simulator study. The Open Transportation Journal 2:53-64. DOI: 10.2174/1874447800802010053

Alicandri E, Moyer J. 1992. Human factors and the automated highway system. Proceedings of the Human Factors and Ergonomics Society Annual Meeting 36:1064-1067. DOI: $10.1518 / 107118192786749793$

Arrabito GR. 2009. Effects of talker sex and voice style of verbal cockpit warnings on performance. Human Factors 51: 3-20. DOI: 10.1177/0018720808333411

Bainbridge L. 1983. Ironies of automation. Automatica 19:775-779. DOI: 10.1016/00051098(83)90046-8

Banks VA, Stanton NA, Harvey C. 2014. Sub-systems on the road to vehicle automation: Hands and feet free but not 'mind' free driving. Safety Science 62:505-514. DOI: 10.1016/j.ssci.2013.10.014

Barón A, Green P. 2006. Safety and usability of speech interfaces for in-vehicle tasks while driving: A brief literature review (Technical Report No. UMTRI-2006-5). Ann Arbor, MI: Transportation Research Institute, University of Michigan. Available at http://www.umich.edu/ driving/publications/UMTRI-2006-5a.pdf(accessed 13 July 2015)

Begault DR. 1993. Head-up auditory displays for traffic collision avoidance system advisories: A preliminary investigation. Human Factors 35:707-717. DOI: $10.1177 / 001872089303500409$

Beiker SA. 2012. Legal aspects of autonomous driving: The need for a legal infrastructure that permits autonomous driving in public to maximize safety and consumer benefit. Santa Clara Law Review 52:1145-1561

Belz SM, Robinson GS, Casali JG. 1999. A new class of auditory warning signals for complex systems: Auditory icons. Human Factors 41:608-618. DOI: 10.1518/001872099779656734

Bergenhem C, Pettersson H, Coelingh E, Englund C, Shladover S, Tsugawa S. 2012. Overview of platooning systems. In: Proceedings of the 19th ITS World Congress, Vienna, Austria. Available at http://publications.lib.chalmers.se/records/fulltext/174621/local_174621.pdf (accessed 13 July 2015)

BMW. 2013. BMW ConnectedDrive from A to Z. Available at http://www.bmw.com/com/en/insights/technology/connecteddrive/2013/a_to_z/index.html (accessed 7 November 2014) 
BMW. 2014. BMW X5: Park Assistant. Available at http://www.bmw.com/com/en/newvehicles/x/x5/2013/showroom/driver_assistance/park_assi stant.html $\# t=l$ (accessed 12 November 2014)

Bosker B. 2013. Why Siri's voice is now a man (and a woman). Available at http://www.huffingtonpost.com/2013/06/11/siri-voice-man-woman_n_3423245.html (accessed 18 December 2014)

Braitman KA, McCartt AT, Zuby DS, Singer J. 2010. Volvo and Infiniti drivers' experiences with select crash avoidance technologies. Traffic Injury Prevention 11:270-278. DOI: $10.1080 / 15389581003735600$

Brandenburg S, Skottke E. 2014. Switching from manual to automated driving and reverse: Are drivers behaving more risky after highly automated driving? In: Proceedings of the IEEE 17th International Conference on Intelligent Transportation Systems (ITSC), Qingdao, China. 2978-2983. DOI: 10.1109/ITSC.2014.6958168

Bregman AS. 1990. Auditory scene analysis: The perceptual organization of sound. Cambridge, MA: MIT Press

Bronkhorst AW, Veltman JA, Van Breda L. 1996. Application of a three-dimensional auditory display in a flight task. Human Factors 38:23-33. DOI: 10.1518/001872096778940859

Clarke DD, Ward P, Truman W. 2005. Voluntary risk taking and skill deficits in young driver accidents in the UK. Accident Analysis \& Prevention 37:523-529. DOI: 10.1016/j.aap.2005.01.007

Continental. 2012. Continental strategy focuses on automated driving. Available at https://www.contionline.com/www/pressportal_com_en/themes/press_releases/1_topics/automated_driving_e n/pr_2012_12_18_automated_driving_en.html (accessed 8 November 2014)

Cooke M, Ellis DPW. 2001. The auditory organization of speech and other sources in listeners and computational models. Speech Communication 35:141-177. DOI: 10.1016/S01676393(00)00078-9

Crump MJC, McDonnell JV, Gureckis TM. 2013. Evaluating Amazon's Mechanical Turk as a tool for experimental behavioral research. PLOS ONE 8: e57410. DOI: 10.1371/journal.pone.0057410

Dagan E, Mano O, Stein GP, Shashua A. 2004. Forward collision warning with a single camera. IEEE Intelligent Vehicles Symposium, 2004, Parma, Italy. 71-79. DOI: 10.1109/IVS.2004.1336352 
Daimler. 2013. DISTRONIC PLUS: warns and assists the driver. Available at http://www.daimler.com/dccom/0-5-1210218-1-1210321-1-0-0-1210228-0-0-135-0-0-0-00-0-0-0.html (accessed 7 November 2014)

De Winter JCF. 2013. Predicting self-reported violations among novice license drivers using prelicense simulator measures. Accident Analysis \& Prevention 52:71-79. DOI: 10.1016/j.aap.2012.12.018

De Winter JCF, Happee R, Martens MH, Stanton NA. 2014. Effects of adaptive cruise control and highly automated driving on workload and situation awareness: A review of the empirical evidence. Transportation Research Part F: Traffic Psychology and Behaviour 27:196-217. DOI: 10.1016/j.trf.2014.06.016

De Winter JCF, Kyriakidis M, Dodou D, Happee R. 2015. Using CrowdFlower to study the relationship between self-reported violations and traffic accidents. In: Proceedings of the 6th International Conference on Applied Human Factors and Ergonomics (AHFE), Las Vegas, $N V$.

Desmond P, Hancock P, Monette J. 1998. Fatigue and automation-induced impairments in simulated driving performance. Transportation Research Record: Journal of the Transportation Research Board 1628:8-14. DOI: 10.3141/1628-02

Dingus TA, Hulse MC, Barfield W. 1998. Human-system interface issues in the design and use of advanced traveler information systems. In: Barfield W, Dingus TA, eds. Human Factors in Intelligent Transportation Systems. Mahwah, NJ: Lawrence Erlbaum Associates, 359395

Dobler D, Haller M, Stampfl P. 2002. ASR - augmented sound reality [abstract]. In: Conference abstracts and applications on - SIGGRAPH '02. New York, NY: ACM Press, 148

Ebbatson M. 2009. The loss of manual flying skills in pilots of highly automated airliners. PhD Thesis, Cranfield University

Edworthy J, Hellier E, Rivers J. (2003). The use of male or female voices in warnings systems: a question of acoustics. Noise \& Health 6:39-50.

European Commision. 2011. Roadmap to a single European transport area-towards a competitive and resource efficient transport system (White Paper, COM(2011) 144 final) Brussels

Ford. 2014. Collision warning with brake support. Available at http://support.ford.com/maintenance/collision-warning-brake-support (accessed 11 January 2015)

Garas J. 2000. Adaptive 3D sound systems. Kluwer Academic Publishers. DOI: 10.1007/978-14419-8776-1 
Gasser T, Westhoff D. 2012. BASt-study: definitions of automation and legal issues in Germany. Presented at the 2012 Road Vehicle Automation Workshop, Transportation Research Board. Available at http://onlinepubs.trb.org/onlinepubs/conferences/2012/Automation/presentations/Gasser.pd $f$ (accessed 13 July 2015)

Godinho L, António J, Tadeu A. 2001. 3D sound scattering by rigid barriers in the vicinity of tall buildings. Applied Acoustics 62:1229-1248. DOI: 10.1016/S0003-682X(01)00004-4

Gold C, Damböck D, Lorenz L, Bengler K. 2013. "Take over!” How long does it take to get the driver back into the loop? Proceedings of the Human Factors and Ergonomics Society Annual Meeting 57:1938-1942. DOI: 10.1177/1541931213571433

Gomes L. 2014. Google self-driving car: It may never actually happen. Available at http://www.slate.com/articles/technology/technology/2014/10/google_self_driving_car_it_ may_never_actually_happen.html (accessed 17 December 2014)

Goodall NJ. 2014. Machine ethics and automated vehicles. In: Meyer G, Beiker S, eds. Road Vehicle Automation. Springer International Publishing, 93-102. DOI: 10.1007/978-3-31905990-7 9

Gururaj G. 2008. Road traffic deaths, injuries and disabilities in India: Current scenario. National Medical Journal of India 21:14-20

Heikoop D, De Winter JCF, Van Arem B, Stanton NA. 2015. Psychological constructs in driving automation: A consensus model and critical comment on construct proliferation. Manuscript submitted for publication.

Hermann T, Hunt A, Neuhoff J. 2011. The sonification handbook. Berlin: Logos Publishing House

Ho C, Reed N, Spence C. 2007. Multisensory in-car warning signals for collision avoidance. Human Factors 49:1107-1114. DOI: 10.1518/001872007X249965

Holland S, Morse DR, Gedenryd H. 2002. AudioGPS: spatial audio navigation with a minimal attention interface. Personal and Ubiquitous Computing 6:253-259. DOI: $10.1007 / \mathrm{s} 007790200025$

Honda. 2014. Forward Collision Warning. Available at http://owners.honda.com/vehicles/information/2014/Accord-Coupe/features/ForwardCollision-Warning/3 (accessed 10 November 2014)

Howe J. 2006. The rise of crowdsourcing. Wired Magazine 14:1-4 
Jamson AH, Merat N, Carsten O, Lai FCH. 2011. Fully-automated driving: The road to future vehicles. In: Proceedings of the Sixth International Driving Symposium on Human Factors in Driver Assessment, Training and Vehicle Design, Olympic Valley - Lake Tahoe, CA. 2-9

Jamson AH, Lai FCH, Carsten OMJ. 2008. Potential benefits of an adaptive forward collision warning system. Transportation Research Part C: Emerging Technologies 16:471-484. DOI: $10.1016 /$ j.trc.2007.09.003

Jonsson I-M, Dahlbäck N. 2011. I can’t hear you? drivers interacting with male or female voices in native or non-native language. In: Stephanidis C, ed. Universal access in humancomputer interaction. Context diversity. Berlin Heidelberg: Springer-Verlag, 298-305

Kessler C, Etemad A, Alessandretti G, Heinig K, Selpi, Brouwer R, Cserpinszky, Hagleitner W, Benmimoun M. 2012. euroFOT - final report (Deliverable D11.3). Aachen, Germany. Available at http://www.eurofotip.eu/download/library/deliverables/eurofotsp120121212v11dld113_final_report.pdf (accessed 13 July 2015)

Kingsley K. 2009. Evaluating crash avoidance countermeasures using data from FMCSA/NHTSA's large truck crash causation study. In: 21st International Technical Conference on the Enhanced Safety of Vehicles Conference, Stuttgart, Germany. Available at http://www-nrd.nhtsa.dot.gov/pdf/ESV/esv21/09-0460.pdf (accessed 13 July 2015)

Kittur A, Chi EH, Suh B. 2008. Crowdsourcing user studies with Mechanical Turk. In: Proceedings of the SIGCHI Conference on Human Factors in Computing Systems. New York, NY: ACM Press, 453-456

Kulas JT, Stachowski AA. 2009. Middle category endorsement in odd-numbered Likert response scales: Associated item characteristics, cognitive demands, and preferred meanings. Journal of Research in Personality 43:489-493. DOI: 10.1016/j.jrp.2008.12.005

Kulas JT, Stachowski AA, Haynes BA. 2008. Middle response functioning in likert-responses to personality items. Journal of Business and Psychology 22:251-259. DOI: 10.1007/s10869008-9064-2

Kyriakidis M, Happee R, De Winter JCF. 2015. Public opinion on automated driving: Results of an international questionnaire among 5000 respondents. Transportation Research Part F: Traffic Psychology and Behaviour 32:127-140. DOI: 10.1016/j.trf.2015.04.014

Large DR, Burnett GE. 2013. Drivers' preferences and emotional responses to satellite navigation voices. International Journal of Vehicle Noise and Vibration 9:28-46.

Larsson AF, Kircher K, Hultgren JA. 2014. Learning from experience: Familiarity with ACC and responding to a cut-in situation in automated driving. Transportation Research Part F: Traffic Psychology and Behaviour 27:229-237. DOI: 10.1016/j.trf.2014.05.008 
Lee AH, Stevenson MR, Wang K, Yau KKW. 2002. Modeling young driver motor vehicle crashes: data with extra zeros. Accident Analysis \& Prevention 34:515-521. DOI: 10.1016/S0001-4575(01)00049-5

Lee JD. 2007. Technology and teen drivers. Journal of Safety Research 38:203-213. DOI: 10.1016/j.jsr.2007.02.008

Levitan L, Golembiewski G, Bloomfield JR. 1998. Human factors issues for automated highway systems. ITS Journal 4:21-47. DOI: 10.1080/10248079808903735

Llaneras RE, Salinger JA, Green CA. 2013. Human factors issues associated with limited ability autonomous driving systems: Drivers' allocation of visual attention to the forward roadway. In: Proceedings of the 7th International Driving Symposium on Human Factors in Driver Assessment, Training and Vehicle Design, Bolton Landing, NY. 92-98.

Lumbreras M, Sánchez J, Barcia M. 1996. A 3D sound hypermedial system for the blind. In: Proceedings of the First European Conference on Disability, Virtual Reality and Associated Technologies, Maidenhead, UK. 187-191. Available at http://www.icdvrat.org/1996/papers/1996_22.pdf(accessed 13 July 2015)

Markoff J. 2010. Google cars drive themselves, in traffic. The New York Times. Available at http://www.nytimes.com/2010/10/10/science/10google.html (accessed 13 July 2015)

Mason W, Suri S. 2012. Conducting behavioral research on Amazon's Mechanical Turk. Behavior Research Methods 44:1-23. DOI: 10.3758/s13428-011-0124-6

Matthews ML, Moran AR. 1986. Age differences in male drivers' perception of accident risk: The role of perceived driving ability. Accident Analysis \& Prevention 18:299-313. DOI: 10.1016/0001-4575(86)90044-8

Merat N, Jamson AH, Lai FC, Carsten O. 2012. Highly automated driving, secondary task performance, and driver state. Human Factors: The Journal of the Human Factors and Ergonomics Society 54:762-771. DOI: 10.1177/0018720812442087

Mercedes-Benz. 2014. Pre-Safe. Available at http://www2.mercedesbenz.co.uk/content/unitedkingdom/mpc/mpc_unitedkingdom_website/en/home_mpc/passeng ercars/home/corporate_sales0/fleet/leasing/our_advantages/Safety.0009.html (accessed 12 November 2014)

Miller R, Huang Q. 2002. An adaptive peer-to-peer collision warning system. In: Proceedings of the IEEE 55th Vehicular Technology Conference, 2002, Birmingham, AL. 317-321. DOI: 10.1109/VTC.2002.1002718

Mynatt ED. 1990. Auditory presentation of graphical user interfaces. Available at https://smartech.gatech.edu/bitstream/handle/1853/3681/92-26.pdf(accessed 12 July 2015) 
Nixon CW, Morris LJ, McCavitt AR, McKinley RL, Anderson TR, McDaniel MP, Yeager DG. 1998a. Female voice communications in high levels of aircraft cockpit noises - part I: spectra, levels, and microphones. Aviation, Space, and Environmental Medicine 69:675-683

Nixon CW, Anderson TR, Morris LJ, McCavitt A, McKinley RL, Yeager DG, McDaniel MP. 1998b. Female voice communications in high level aircraft cockpit noises - part II: vocoder and automatic speech recognition systems. Aviation, Space, and Environmental Medicine 69:1087-1094

Noyes JM, Hellier E, Edworthy J. 2006. Speech warnings: a review. Theoretical Issues in Ergonomics Science 7:551-571. DOI: 10.1080/14639220600731123

Norman DA. 1990. The 'problem' with automation: inappropriate feedback and interaction, not 'over-automation'. Philosophical Transactions of the Royal Society of London. B, Biological Sciences 327:585-593. DOI: 10.1098/rstb.1990.0101

Payre W, Cestac J, Delhomme P. 2014. Intention to use a fully automated car: Attitudes and a priori acceptability. Transportation Research Part F: Traffic Psychology and Behaviour 27:252-263. DOI: 10.1016/j.trf.2014.04.009

Rozier JM. 2000. Hear\&There: An augmented reality system of linked audio. MSc Thesis, Cambridge, MA: MIT

Rudin-Brown CM, Parker HA. 2004. Behavioural adaptation to adaptive cruise control (ACC): implications for preventive strategies. Transportation Research Part F: Traffic Psychology and Behaviour 7:59-76. DOI: 10.1016/j.trf.2004.02.001

Scallen SF, Hancock PA, Duley JA. 1995. Pilot performance and preference for short cycles of automation in adaptive function allocation. Applied Ergonomics 26:397-403. DOI: 10.1016/0003-6870(95)00054-2

Sommer K. 2013. Mobility study 2013. Available at https://www.contionline.com/www/pressportal_com_en/themes/initiatives/channel_mobility_study_en/ov_mo bility_study2013_en/(accessèd 12 July 2015)

Srinivasa N. 2002. Vision-based vehicle detection and tracking method for forward collision warning in automobiles. IEEE Intelligent Vehicles Symposium, 2002. 626-631. DOI: 10.1109/IVS.2002.1188021

Stanton NA, Young MS, Walker GH, Turner H, Randle S. 2001. Automating the driver's control tasks. International Journal of Cognitive Ergonomics 5:221-236. DOI: 10.1207/S15327566IJCE0503_5

Stanton NA, Edworthy J. 1999. Human factors in auditory warnings. Aldershot, GB: Ashgate 
Stanton NA, Young MS, McCaulder B. 1997. Drive-by-wire: The case of driver workload and reclaiming control with adaptive cruise control. Safety Science 27:149-159. DOI: 10.1016/S0925-7535(97)00054-4

Strand N, Nilsson J, Karlsson ICM, Nilsson L. 2014. Semi-automated versus highly automated driving in critical situations caused by automation failures. Transportation Research Part F: Traffic Psychology and Behaviour 27: 218-228. DOI: 10.1016/j.trf.2014.04.005

Sturgis P, Roberts SC, Smith P. 2012. Middle alternatives revisited: How the neither/nor response acts as a way of saying "I Don't Know"? Sociological Methods \& Research 43:15-38. DOI: 10.1177/0049124112452527

Tacken M, Marcellini F, Mollenkopf H, Ruoppila I, Széman Z. 2005. Use and acceptance of new technology by older people. Findings of the international MOBILATE survey: 'Enhancing mobility in later life'. Gerontechnology 3: 126-137. DOI: 10.4017/gt.2005.03.03.002.00

Takayama L, Nass C. 2008. Driver safety and information from afar: An experimental driving simulator study of wireless vs. in-car information services. International Journal of Human Computer Studies 66:173-184. DOI: 10.1016/j.ijhcs.2006.06.005

Toyota. 2014. Parking. Available at http://www.toyotaglobal.com/innovation/safety_technology/safety_technology/parking/(accessed 10 November 2014)

UK Visas \& Immigration. 2014. Tier 4 of the Points Based System - policy guidance. Available at https://www.gov.uk/government/uploads/system/uploads/attachment_data/file/370866/T4_G uidance_11-14.pdf(accessed 6 February 2015)

Underwood S. 2014. Automated vehicles forecast: Vehicle symposium opinion survey. Paper presented at the Automated Vehicles Symposium 2014, San Francisco, CA. Available at https://drive.google.com/file/d/OB8gGx-CYkV-wREVMTEhHQUxjOWM/edit (accessed 13 July 2015)

Varaiya P. 1993. Smart cars on smart roads. Problems of control. IEEE Transactions on Automatic Control 38:195-207. DOI: 10.1109/9.250509

Volkswagen. 2014. Park assist. Available at http://www.volkswagen.co.uk/technology/parkingand-manoeuvring/park-assist (accessed 10 November 2014)

Volvo. 2013a. Volvo Car Group reveals world-class safety and support features that will be introduced in the all-new XC9. Available at https://www.media.volvocars.com/global/en$\mathrm{gb} /$ media/pressreleases/49875/volvo-cars-reveals-world-class-safety-and-support-featuresto-be-introduced-in-the-all-new-xc90-in-2 (accessed 7 November 2014) 
Volvo. 2013b. One million cars with pioneering auto brake technology sold : Volvo Car Group reaches landmark safety milestone. Available at https://www.media.volvocars.com/uk/engb/media/pressreleases/49817 (accessed 13 July 2015)

Weber M. 2014. Where to? A history of autonomous vehicles. Available at http://www.computerhistory.org/atchm/where-to-a-history-of-autonomous-vehicles/ (accessed 27 December 2014)

Wetmore J. 2003. Driving the dream. The history and motivations behind 60 years of automated highway systems in America. Automotive History Review 7:4-19

Wickens CD, Hollands JG. 2013. Engineering psychology and human performance. New York, NY: HarperCollins Publishers

World Health Organization. 2013. Global status report on road safety 2013. World Health Organization. Available at http://www.who.int/iris/bitstream/10665/78256/1/9789241564564_eng.pdf?ua=1 (accessed 13 July 2015)

Yoshida J. 2014. Fully autonomous car? Don't buy shotgun yet. Available at http://www.eetimes.com/author.asp?section_id $=36 \& d o c \_i d=1322246$ (accessed 17 December 2014) 


\section{1}

Illustrations belonging to the three scenarios presented to the respondents.

(a) Parking assistant (PA); (b) Forward collision warning system (FCWS); (c) Future system (FS).

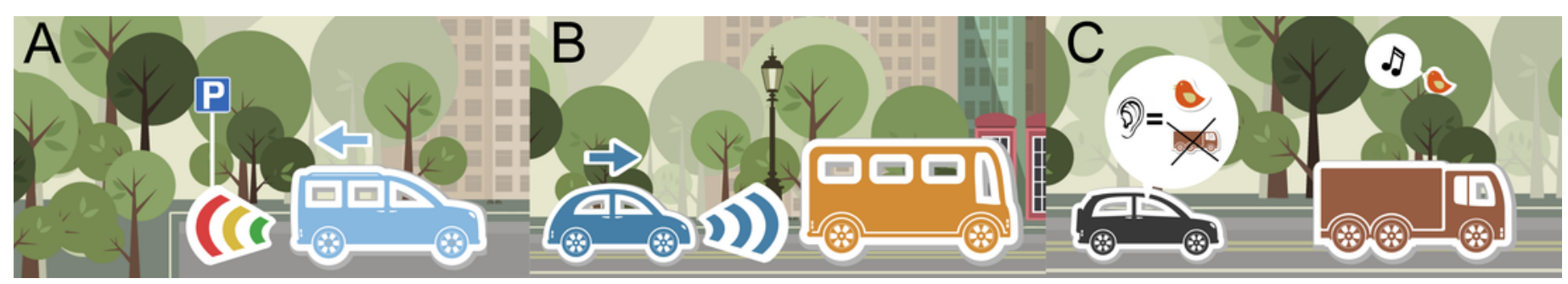




\section{Table 1 (on next page)}

All survey items. 


\begin{tabular}{|c|c|c|c|}
\hline Variable & Question & Full question as reported in the survey & Used coding \\
\hline Instr & Q1 & $\begin{array}{l}\text { Have you read and understood the above } \\
\text { instructions? }\end{array}$ & $1=\mathrm{Yes}, 2=\mathrm{No}$ \\
\hline Gender & Q2 & What is your gender? $(1=$ female, $2=$ male $)$ & $\begin{array}{l}-1=\mathrm{I} \text { prefer not to respond, } 1= \\
\text { Female, } 2=\text { Male }\end{array}$ \\
\hline Age & Q3 & What is your age? & Positive integer value \\
\hline DriveFreq & Q4 & $\begin{array}{l}\text { On average, how often did you drive a } \\
\text { vehicle in the last } 12 \text { months? }\end{array}$ & $\begin{array}{l}-1=\mathrm{I} \text { prefer not to respond, } 1= \\
\text { Never, } 2=\text { Less than once a month, } \\
3=\text { Once a month to once a week, } 4 \\
=1 \text { to } 3 \text { days a week, } 5=4 \text { to } 6 \\
\text { days a week, } 6=\text { Every day }\end{array}$ \\
\hline KmYear & Q5 & $\begin{array}{l}\text { About how many kilometres (miles) did you } \\
\text { drive in the last } 12 \text { months? }\end{array}$ & $\begin{array}{l}-1=\mathrm{I} \text { prefer not to respond, } 1=0,2 \\
=1-1,000,3=1,001-5,000,4= \\
5,001-15,000,5=15,001-20,000, \\
6=20,001-25,000,7=25,001- \\
35,000,8=35,001-50,000,9= \\
50,001-100,000,10=\text { more than } \\
100,000\end{array}$ \\
\hline
\end{tabular}

\begin{tabular}{|c|c|c|c|}
\hline NrAcc & Q6 & $\begin{array}{l}\text { How many accidents were you involved in } \\
\text { when driving a car in the last } 3 \text { years? } \\
\text { (please include all accidents, regardless of } \\
\text { how they were caused, how slight they were, } \\
\text { or where they happened)? }\end{array}$ & $\begin{array}{l}-1=\mathrm{I} \text { prefer not to respond, } 1=0,2 \\
=1,3=2,4=3,5=4,6=5,7= \\
\text { More than } 5\end{array}$ \\
\hline Vangered & Q7 & $\begin{array}{l}\text { How often do you do the following?: } \\
\text { Becoming angered by a particular type of } \\
\text { driver, and indicate your hostility by } \\
\text { whatever means you can. }\end{array}$ & $\begin{array}{l}-1=\mathrm{I} \text { prefer not to respond, } 1=0 \\
\text { times per month, } 2=1 \text { to } 3 \text { times } \\
\text { per month, } 3=4 \text { to } 6 \text { times per } \\
\text { month, } 4=7 \text { to } 9 \text { times per month, } \\
5=10 \text { or more times per month }\end{array}$ \\
\hline Vmotorway & Q8 & $\begin{array}{l}\text { How often do you do the following?: } \\
\text { Disregarding the speed limit on a motorway. }\end{array}$ & $\begin{array}{l}-1=\mathrm{I} \text { prefer not to respond, } 1=0 \\
\text { times per month, } 2=1 \text { to } 3 \text { times } \\
\text { per month, } 3=4 \text { to } 6 \text { times per } \\
\text { month, } 4=7 \text { to } 9 \text { times per month, } \\
5=10 \text { or more times per month }\end{array}$ \\
\hline Vresident & Q9 & $\begin{array}{l}\text { How often do you do the following?: } \\
\text { Disregarding the speed limit on a residential } \\
\text { road. }\end{array}$ & $\begin{array}{l}-1=\mathrm{I} \text { prefer not to respond, } 1=0 \\
\text { times per month, } 2=1 \text { to } 3 \text { times } \\
\text { per month, } 3=4 \text { to } 6 \text { times per } \\
\text { month, } 4=7 \text { to } 9 \text { times per month, } \\
5=10 \text { or more times per month }\end{array}$ \\
\hline Vfollowing & Q10 & $\begin{array}{l}\text { How often do you do the following?: } \\
\text { Driving so close to the car in front that it } \\
\text { would be difficult to stop in an emergency. }\end{array}$ & $\begin{array}{l}-1=\mathrm{I} \text { prefer not to respond, } 1=0 \\
\text { times per month, } 2=1 \text { to } 3 \text { times } \\
\text { per month, } 3=4 \text { to } 6 \text { times per } \\
\text { month, } 4=7 \text { to } 9 \text { times per month, } \\
5=10 \text { or more times per month }\end{array}$ \\
\hline Vrace & Q11 & How often do you do the following?: Racing & $-1=\mathrm{I}$ prefer not to respond, $1=0$ \\
\hline
\end{tabular}


away from traffic lights with the intention of times per month, $2=1$ to 3 times beating the driver next to you. per month, $3=4$ to 6 times per month, $4=7$ to 9 times per month, $5=10$ or more times per month

\begin{tabular}{lll}
\hline Vhorn & Q12 & $\begin{array}{l}\text { How often do you do the following?: } \\
\text { Sounding your horn to indicate your } \\
\text { annoyance with another road user. }\end{array}$ \\
\hline Vphone & Q13 & $\begin{array}{l}\text { How often do you do the following?: Using } \\
\text { a mobile phone without a hands free kit. }\end{array}$
\end{tabular}

$-1=\mathrm{I}$ prefer not to respond, $1=0$ times per month, $2=1$ to 3 times per month, $3=4$ to 6 times per month, $4=7$ to 9 times per month, $5=10$ or more times per month

a mobile phone without a hands free kit.

$-1=$ I prefer not to respond, $1=0$ times per month, $2=1$ to 3 times per month, $3=4$ to 6 times per month, $4=7$ to 9 times per month, $5=10$ or more times per month

\begin{tabular}{|c|c|c|c|}
\hline Vmean & N/A & Mean for Q7-12 & Numeric value \\
\hline PApast & Q14 & $\begin{array}{l}\text { In the past month, did you drive a car with a } \\
\text { parking assistant? }\end{array}$ & $\begin{array}{l}-1=\mathrm{I} \text { prefer not to respond, } 1=\mathrm{I} \text { do } \\
\text { not know, } 2=\text { No, } 3=\text { Yes }\end{array}$ \\
\hline PAhelp & Q15 & A parking assistant is helpful. & $\begin{array}{l}-1=\mathrm{I} \text { prefer not to respond, } 1= \\
\text { Disagree strongly, } 2=\text { Disagree a } \\
\text { little, } 3=\text { Neither agree nor } \\
\text { disagree, } 4=\text { Agree a little, } 5= \\
\text { Agree strongly }\end{array}$ \\
\hline PAannoy & Q16 & A parking assistant is annoying. & $\begin{array}{l}-1=\mathrm{I} \text { prefer not to respond, } 1= \\
\text { Disagree strongly, } 2=\text { Disagree a } \\
\text { little, } 3=\text { Neither agree nor } \\
\text { disagree, } 4=\text { Agree a little, } 5= \\
\text { Agree strongly }\end{array}$ \\
\hline PAopin & Q17 & $\begin{array}{l}\text { What do you think are the disadvantages of a } \\
\text { parking assistant? }\end{array}$ & Textual response \\
\hline PAfut & Q18 & $\begin{array}{l}\text { I would like to have a system in my car that } \\
\text { can park the car automatically, just by } \\
\text { pressing a button. }\end{array}$ & $\begin{array}{l}-1=\mathrm{I} \text { prefer not to respond, } 1= \\
\text { Disagree strongly, } 2=\text { Disagree a } \\
\text { little, } 3=\text { Neither agree nor } \\
\text { disagree, } 4=\text { Agree a little, } 5= \\
\text { Agree strongly }\end{array}$ \\
\hline FCWSpast & Q19 & $\begin{array}{l}\text { In the past month, did you drive a car with a } \\
\text { forward collision warning system? }\end{array}$ & $\begin{array}{l}-1=\mathrm{I} \text { prefer not to respond, } 1=\mathrm{I} \text { do } \\
\text { not know, } 2=\text { No, } 3=\text { Yes }\end{array}$ \\
\hline FCWShelp & Q20 & $\begin{array}{l}\text { A forward collision warning system is } \\
\text { helpful. }\end{array}$ & $\begin{array}{l}-1=\mathrm{I} \text { prefer not to respond, } 1= \\
\text { Disagree strongly, } 2=\text { Disagree a } \\
\text { little, } 3=\text { Neither agree nor } \\
\text { disagree, } 4=\text { Agree a little, } 5= \\
\text { Agree strongly }\end{array}$ \\
\hline FCWSannoy & Q21 & $\begin{array}{l}\text { A forward collision warning system is } \\
\text { annoying. }\end{array}$ & $\begin{array}{l}-1=\mathrm{I} \text { prefer not to respond, } 1= \\
\text { Disagree strongly, } 2=\text { Disagree a } \\
\text { little, } 3=\text { Neither agree nor }\end{array}$ \\
\hline
\end{tabular}




\begin{tabular}{|c|c|c|c|}
\hline & & & $\begin{array}{l}\text { disagree, } 4=\text { Agree a little, } 5= \\
\text { Agree strongly }\end{array}$ \\
\hline FCWSfut & Q22 & $\begin{array}{l}\text { I would you like to have a system in my car } \\
\text { that brakes automatically to avoid collisions } \\
\text { (Autonomous Emergency Braking). }\end{array}$ & $\begin{array}{l}-1=\mathrm{I} \text { prefer not to respond, } 1= \\
\text { Disagree strongly, } 2=\text { Disagree a } \\
\text { little, } 3=\text { Neither agree nor } \\
\text { disagree, } 4=\text { Agree a little, } 5= \\
\text { Agree strongly }\end{array}$ \\
\hline FCWSopin & Q23 & $\begin{array}{l}\text { What do you think are the disadvantages of a } \\
\text { forward collision warning system? }\end{array}$ & Textual response \\
\hline FSannoy & Q24 & $\begin{array}{l}\text { I believe that this type of surround sound } \\
\text { system would be annoying. }\end{array}$ & $\begin{array}{l}-1=\mathrm{I} \text { prefer not to respond, } 1= \\
\text { Disagree strongly, } 2=\text { Disagree a } \\
\text { little, } 3=\text { Neither agree nor } \\
\text { disagree, } 4=\text { Agree a little, } 5= \\
\text { Agree strongly }\end{array}$ \\
\hline FSfut & Q25 & $\begin{array}{l}\text { I would prefer to use such a sound system } \\
\text { instead of opening the window, when driving } \\
\text { through a scenic place (for example, a } \\
\text { national park). }\end{array}$ & $\begin{array}{l}-1=\mathrm{I} \text { prefer not to respond, } 1= \\
\text { Disagree strongly, } 2=\text { Disagree a } \\
\text { little, } 3=\text { Neither agree nor } \\
\text { disagree, } 4=\text { Agree a little, } 5= \\
\text { Agree strongly }\end{array}$ \\
\hline FSopin & Q26 & $\begin{array}{l}\text { What would be the advantages and the } \\
\text { disadvantages of such sound system? }\end{array}$ & Textual response \\
\hline TORint & Q27 & $\begin{array}{l}\text { Now imagine again that you are driving in } \\
\text { an automated car (that can perform certain } \\
\text { tasks without any interaction from the } \\
\text { humans in the car). However, the } \\
\text { automation cannot handle all possible } \\
\text { situations, and you sometimes have to take } \\
\text { over control. What type of warning signal } \\
\text { would you like to receive in case manual } \\
\text { take over is required? }\end{array}$ & $\begin{array}{l}1=\text { Warning sound: one beep, } 2= \\
\text { Warning sound: two beeps, } 3= \\
\text { Warning sound: horn sound, } 4= \\
\text { Warning sound: bell sound, } 5= \\
\text { Warning light, } 6=\text { Visual warning } \\
\text { message projected on windscreen } \\
\text { 'Take over please', } 7=\text { Vibrations } \\
\text { in your seat, } 8=\text { Vibrations in your } \\
\text { steering wheel, } 9=\text { Vibrations in } \\
\text { your seatbelt, } 10=\text { Vibrations in the } \\
\text { floor, } 11=\text { Female voice: 'Take } \\
\text { over please', } 12=\text { Male voice: } \\
\text { 'Take over please', } 13=\text { Other, } 14 \\
=\text { None of the above }\end{array}$ \\
\hline TORintot & Q28 & $\begin{array}{l}\text { If you answered 'Other' in the previous } \\
\text { question, please specify what type of } \\
\text { warning signal you would like to receive in } \\
\text { the described scenario. }\end{array}$ & Textual response \\
\hline FACpref & Q29 & $\begin{array}{l}\text { I would prefer to drive in a fully automated } \\
\text { car rather than a normal (non automated) car. }\end{array}$ & $\begin{array}{l}-1=\mathrm{I} \text { prefer not to respond, } 1= \\
\text { Disagree strongly, } 2=\text { Disagree a } \\
\text { little, } 3=\text { Neither agree nor } \\
\text { disagree, } 4=\text { Agree a little, } 5= \\
\text { Agree strongly }\end{array}$ \\
\hline YearAuto & Q30 & $\begin{array}{l}\text { In which year do you think that most cars } \\
\text { will be able to drive fully automatically in }\end{array}$ & Year \\
\hline
\end{tabular}


your country of residence?

Comm Q31 Please provide any suggestions which could Textual response help engineers to build safe and enjoyable automated cars.

SurvTime

Survey time (derived from results generated Seconds

by Crowdflower)

1 
Table 2 (on next page)

Descriptive statistics for the survey items $(N=1,205)$.

The response option "I don't know" was omitted for the variables PApast and FCWSpast. 


\begin{tabular}{|c|c|c|c|c|c|c|}
\hline Variable & Mean & Median & SD & Skewness & Min & Max \\
\hline Gender & 1.75 & 2 & 0.43 & -1.17 & 1 & 2 \\
\hline Age & 31.94 & 30 & 10.49 & 1.04 & 18 & 73 \\
\hline DriveFreq & 4.72 & 5 & 1.21 & -0.66 & 2 & 6 \\
\hline KmYear & 4.09 & 4 & 1.78 & 0.92 & 2 & 10 \\
\hline NrAcc & 1.47 & 1 & 0.94 & 2.88 & 1 & 7 \\
\hline Vangered & 1.86 & 2 & 0.86 & 1.46 & 1 & 5 \\
\hline Vmotorway & 1.85 & 2 & 1.05 & 1.54 & 1 & 5 \\
\hline Vresident & 1.70 & 1 & 1.01 & 1.79 & 1 & 5 \\
\hline Vfollowing & 1.45 & 1 & 0.77 & 2.07 & 1 & 5 \\
\hline Vrace & 1.32 & 1 & 0.69 & 2.62 & 1 & 5 \\
\hline Vhorn & 1.86 & 2 & 1 & 1.41 & 1 & 5 \\
\hline Vphone & 1.64 & 1 & 1.01 & 1.84 & 1 & 5 \\
\hline Vmean & 1.67 & 1.57 & 0.57 & 1.36 & 1 & 4.71 \\
\hline PApast & 2.27 & 2 & 0.45 & 1.03 & 2 & 3 \\
\hline PAhelp & 4.33 & 5 & 0.88 & -1.38 & 1 & 5 \\
\hline PAannoy & 2.35 & 2 & 1.18 & 0.39 & 1 & 5 \\
\hline PAfut & 3.87 & 4 & 1.24 & -0.93 & 1 & 5 \\
\hline FCWSpast & 2.10 & 2 & 0.30 & 2.65 & 2 & 3 \\
\hline FCWShelp & 4.11 & 4 & 1.04 & -1.14 & 1 & 5 \\
\hline FCWSannoy & 2.56 & 3 & 1.26 & 0.27 & 1 & 5 \\
\hline FCWSfut & 3.77 & 4 & 1.22 & -0.80 & 1 & 5 \\
\hline FSannoy & 3.21 & 3 & 1.22 & -0.18 & 1 & 5 \\
\hline FSfut & 3.00 & 3 & 1.29 & -0.09 & 1 & 5 \\
\hline FACpref & 3.01 & 3 & 1.33 & -0.05 & 1 & 5 \\
\hline YearAuto & 2078.33 & 2030 & 713.77 & 30.73 & 2014 & 25000 \\
\hline SurvTime & 553.95 & 462 & 338.41 & 1.34 & 58 & 1810 \\
\hline
\end{tabular}




\section{Table 3 (on next page)}

Frequencies of answers. 


\begin{tabular}{lcccccccccc}
\hline Variable & $\mathbf{1}$ & $\mathbf{2}$ & $\mathbf{3}$ & $\mathbf{4}$ & $\mathbf{5}$ & $\mathbf{6}$ & $\mathbf{7}$ & $\mathbf{8}$ & $\mathbf{9}$ & $\mathbf{1 0}$ \\
\hline Gender & 299 & 906 & & & & & & & & \\
\hline DriveFreq & 0 & 79 & 108 & 293 & 313 & 412 & & & & 7 \\
\hline KmYear & 0 & 250 & 245 & 337 & 148 & 76 & 77 & 49 & 16 & 7 \\
\hline NrAcc & 855 & 226 & 79 & 19 & 13 & 6 & 7 & & \\
\hline Vangered & 417 & 629 & 96 & 33 & 30 & & & & \\
\hline Vmotorway & 541 & 466 & 97 & 39 & 62 & & & & \\
\hline Vresident & 663 & 379 & 78 & 32 & 53 & & & & \\
\hline Vfollowing & 807 & 295 & 70 & 20 & 13 & & & & \\
\hline Vrace & 939 & 182 & 60 & 15 & 9 & & & & \\
\hline Vhorn & 513 & 480 & 123 & 44 & 45 & & & & \\
\hline Vphone & 730 & 304 & 89 & 34 & 48 & & & & \\
\hline PApast & 17 & 865 & 323 & & & & & & \\
\hline PAhelp & 14 & 39 & 134 & 367 & 651 & & & & \\
\hline PAannoy & 383 & 297 & 290 & 196 & 39 & & & & \\
\hline PAfut & 86 & 109 & 175 & 338 & 497 & & & \\
\hline FCWSpast & 28 & 1058 & 119 & & & & & \\
\hline FCWShelp & 34 & 68 & 178 & 373 & 552 & & & \\
\hline FCWSannoy & 331 & 254 & 324 & 208 & 88 & & & & \\
\hline FCWSfut & 82 & 123 & 203 & 377 & 420 & & & & \\
\hline FSannoy & 126 & 218 & 346 & 309 & 206 & & & & \\
\hline FSfut & 204 & 222 & 312 & 301 & 166 & & & & \\
\hline FACpref & 204 & 252 & 264 & 292 & 193 & & & & \\
\hline & & & & & & & & \\
\hline
\end{tabular}


2

Distribution of the age of the respondents aged between 18 and 54 years.

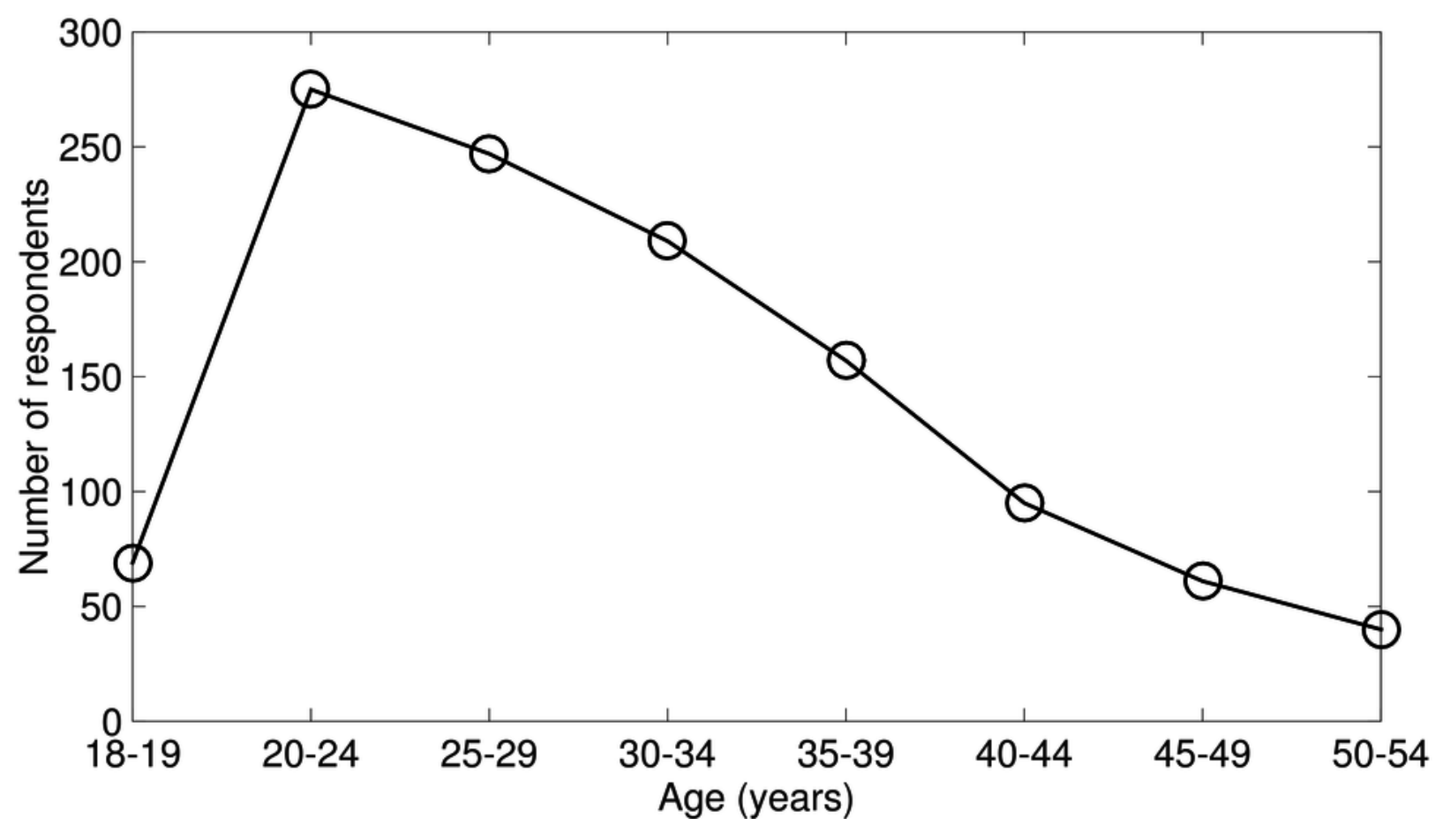


3

Distribution of responses for the question: "In which year do you think that most cars will be able to drive fully automatically in your country of residence?" (Q30).

Years were divided into 5-year-wide bins.

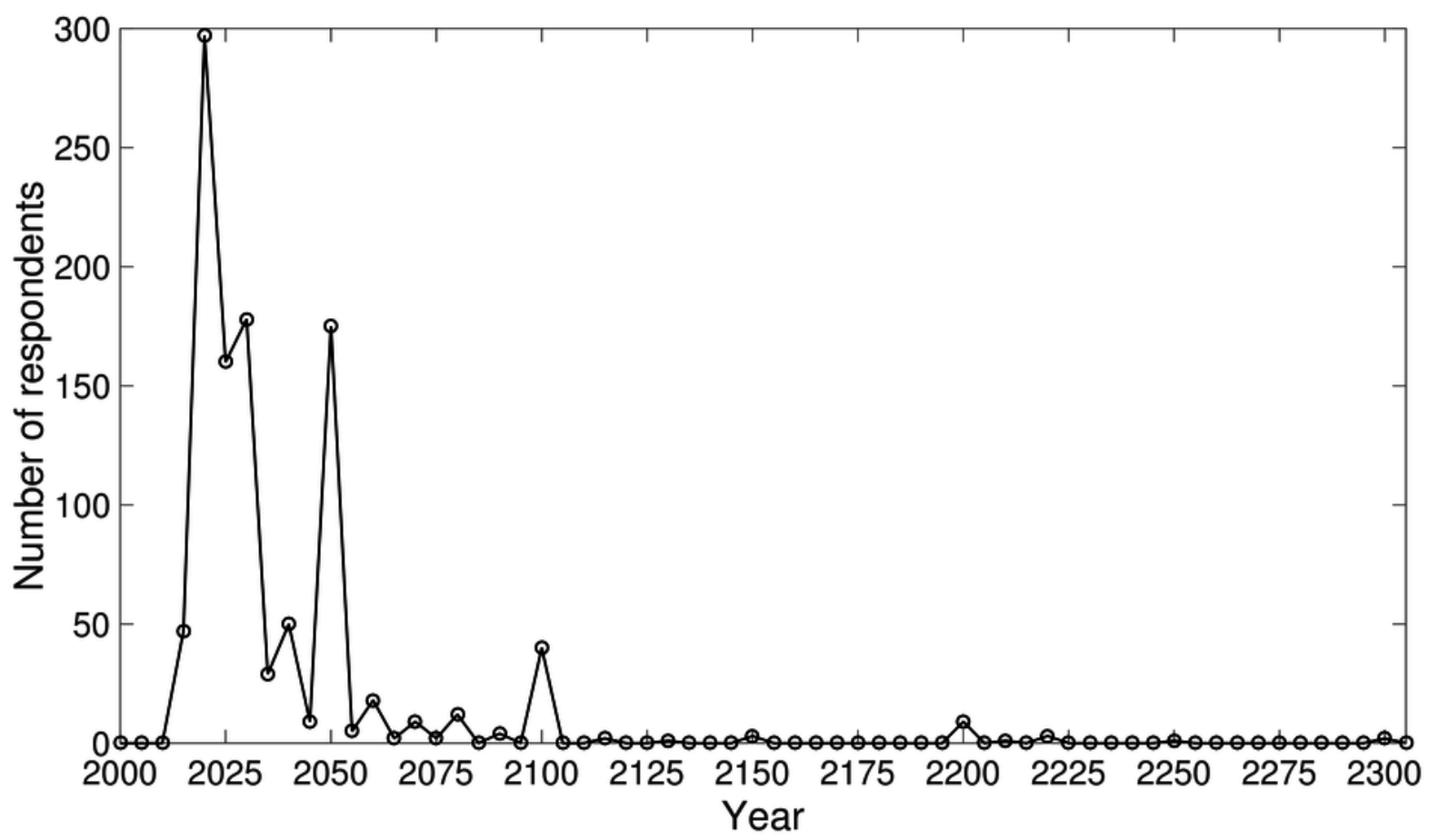


4

Opinion of the respondents on whether a PA and FCWS are helpful and annoying, and whether they would like to have automated versions of such systems in their cars in the future.

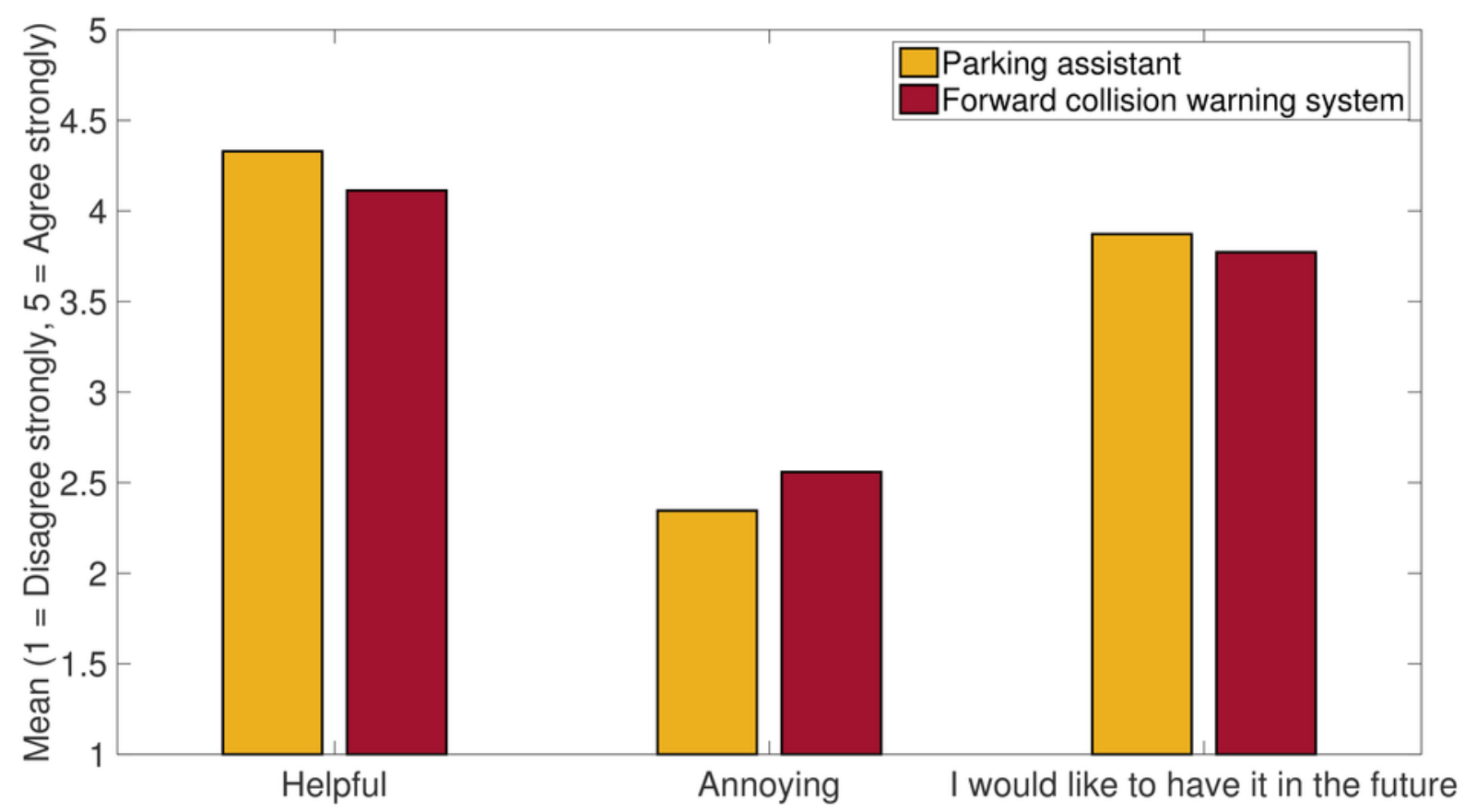




\section{5}

Opinion on the annoyance and helpfulness of the parking assistant (PA), forward collision warning system (FCWS), and future system (FS).

(a) Opinion on the annoyance of the PA (Q16), FCWS (Q21), and FS (Q24) as a function of age; (b) Opinion on the helpfulness of the PA (Q15) and FCWS (Q20) as a function of age. Age was divided into 5-year-wide bins.
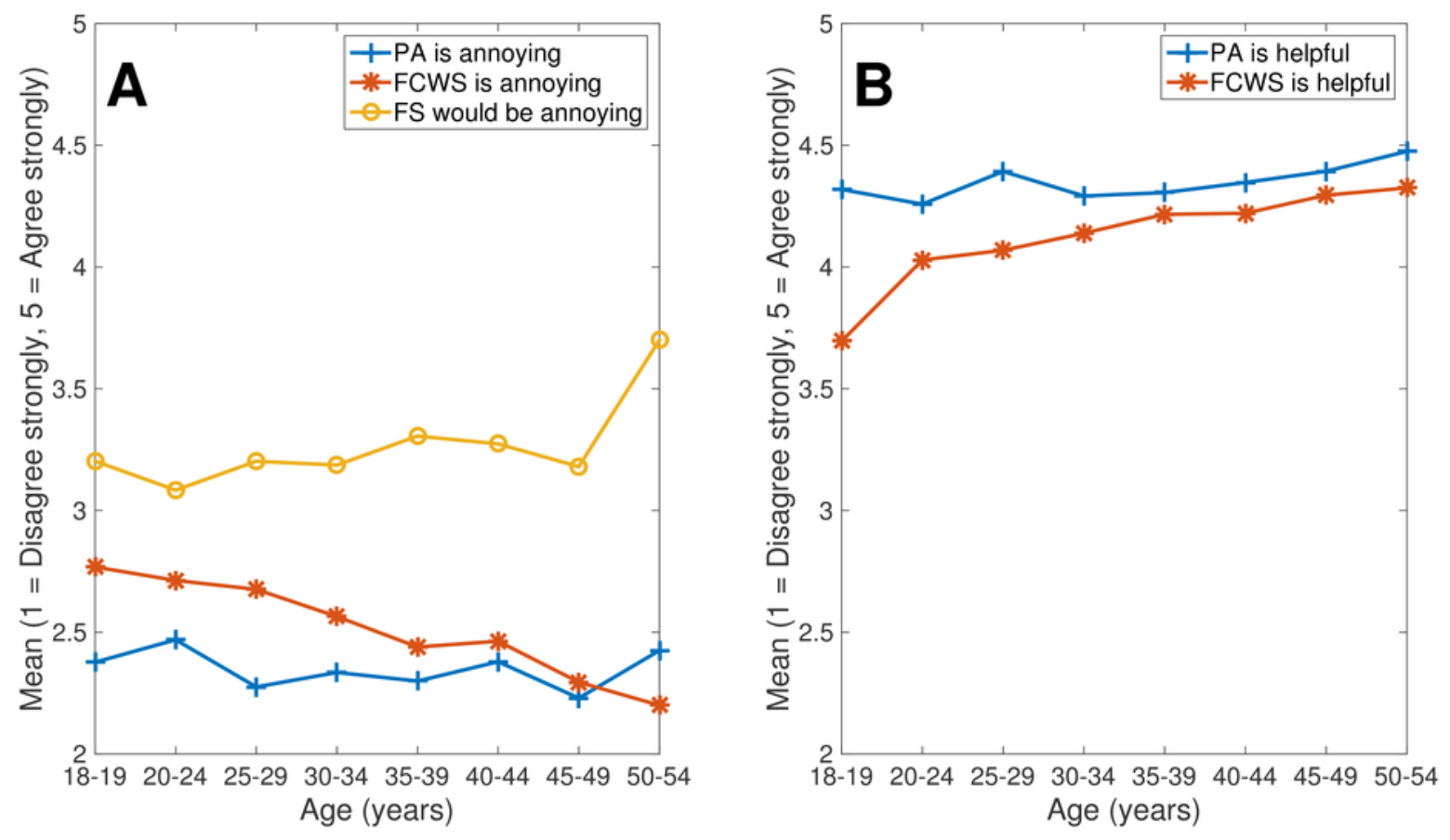
6

Distribution of opinions on whether the proposed future system (FS) would be annoying (Q24) and whether the respondents would prefer the system to opening windows in fully automated cars (Q25).

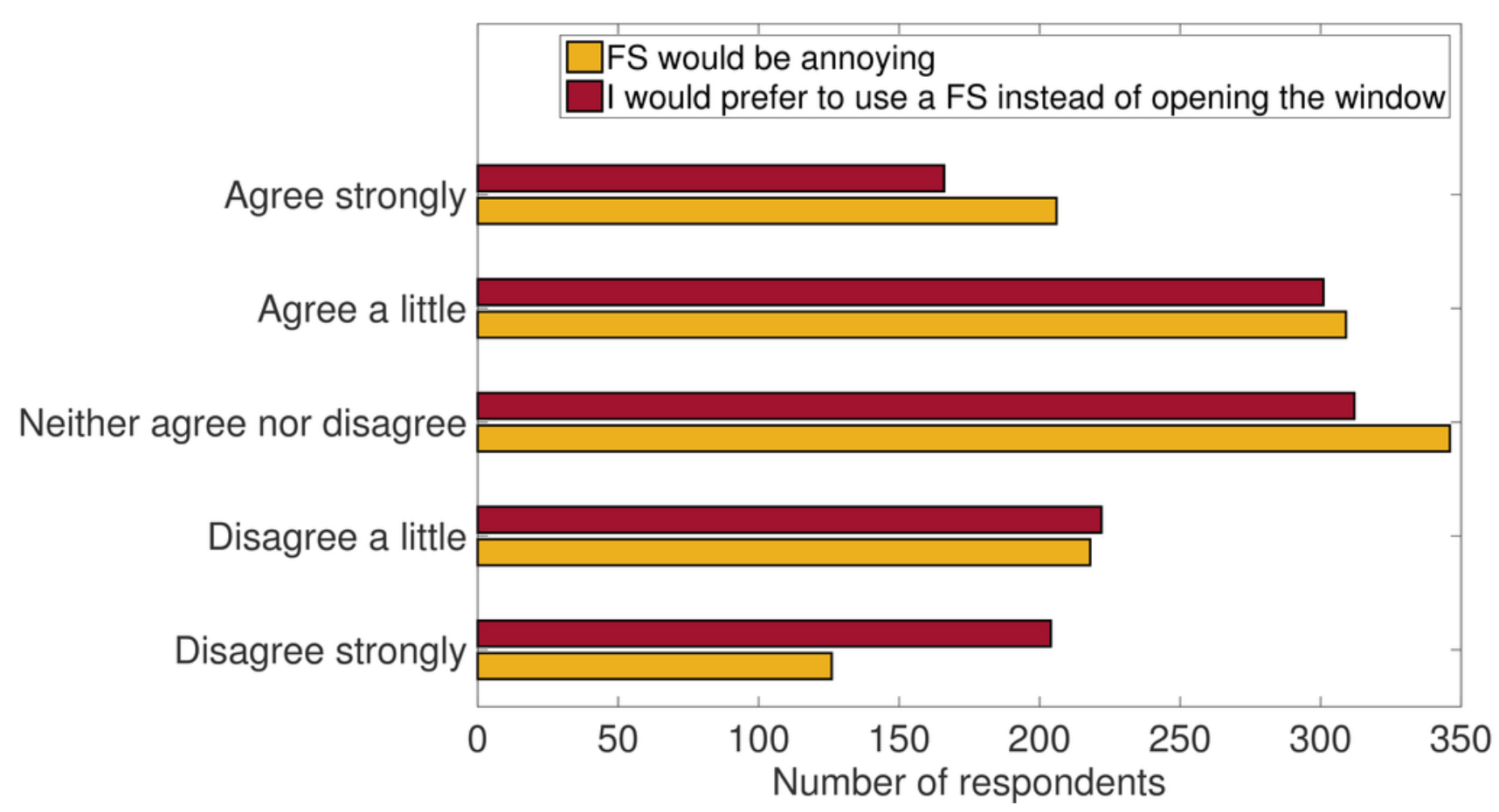


Preference for particular takeover requests during highly automated driving.

Numbers of respondents who indicated a preference for a particular takeover request during highly automated driving in the question: "Now imagine again that you are driving in an automated car (that can perform certain tasks without any interaction from the humans in the car). However, the automation cannot handle all possible situations, and you sometimes have to take over control. What type of warning signal would you like to receive in case manual take over is required?" (Q27). Each bar is supplemented by the corresponding 'risk ratios' of female respondents, calculated as the proportion of females who indicated this answer divided by the number of males who indicated this answer. If the risk ratio is greater than 1 females are overrepresented. Conversely, if the risk ratio is smaller than 1 , females are underrepresented. 95\% confidence intervals are shown in parentheses.

None of the above

Other $\square 0.71(0.24,2.10)$

$\square$ Males

Females

Male voice: "Take over please" Female voice: "Take over please" Vibrations in the floor Vibrations in the seatbelt Vibrations in the steering wheel Vibrations in the seat Visual warning message Warning light Warning sound: bell sound Warning sound: horn sound Warning sound: two beeps Warning sound: one beep 
8

Preference to combinations of types of signals for aiding takeover requests during highly automated driving (Q27).

All possible combinations are listed. Hence, the total number of respondents adds up to 1,205 .

Sound, visual, vibrations, \& voice Visual, vibrations, \& voice Sound, vibrations, \& voice Sound, visual, \& voice Sound, visual, \& vibrations Vibrations \& voice Visual \& voice Visual \& vibrations Sound \& voice Sound \& vibrations Sound \& visual Voice Vibrations Visual Sound None

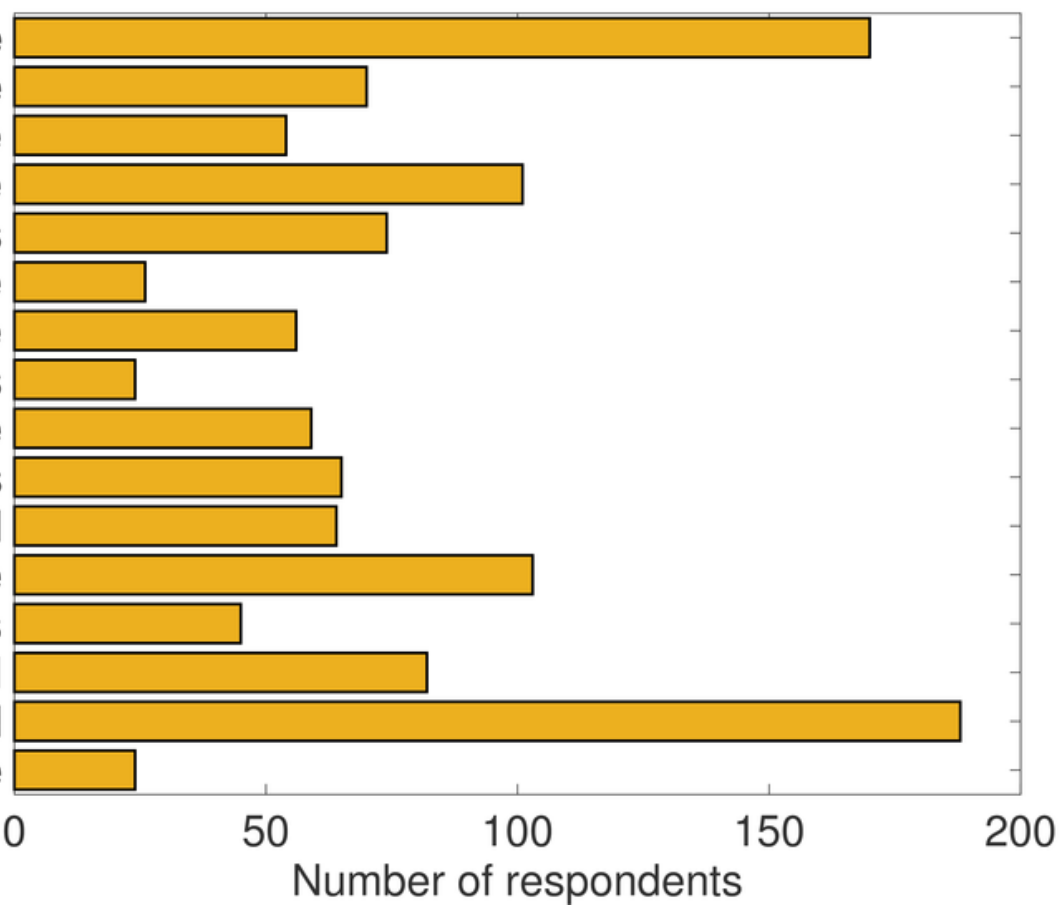




\section{9}

Numbers of respondents from English and non-English speaking countries who indicated a preference for a male and a female voice for a takeover request during highly automated driving (Q27).

The dashed line represents the ratio between the number of respondents who preferred a female voice and the number of respondents who preferred a male voice. The solid line is the line of unity. No labels for shown for countries with five or less respondents indicating a male voice, to support the clarity of the figure. Country abbreviations are listed according to ISO 3166-1 alpha-3.

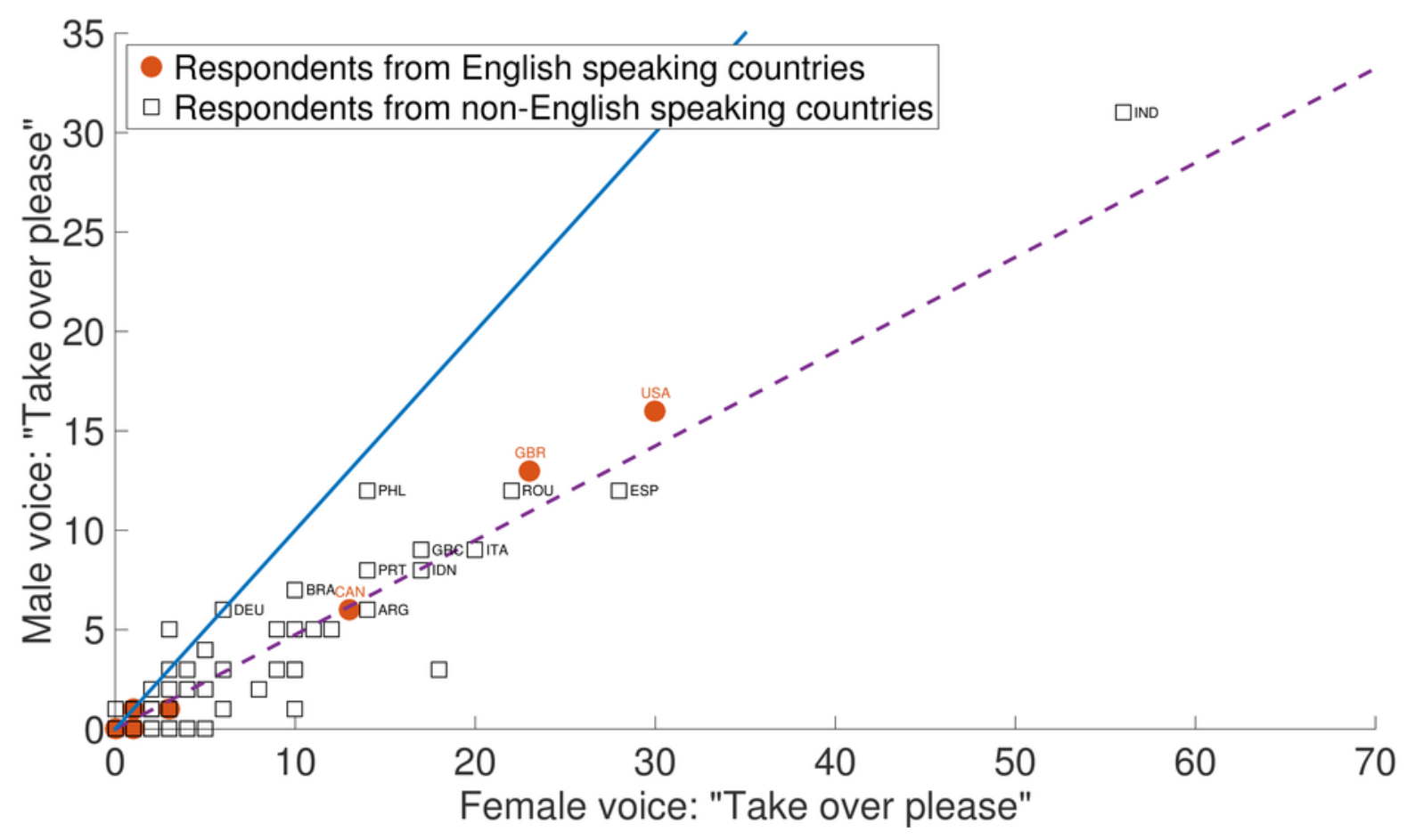

